\title{
REVIEWS \\ Bottom-Up Synthesis and Morphological Control of High-Axial-Ratio Nanostructures through Molecular Self-Assembly
}

\author{
Toshimi SHIMIZU \\ Nanoarchitectonics Research Center (NARC), National Institute of Advanced Industrial Science \\ and Technology (AIST); CREST, Japan Science and Technology Corporation (JST), \\ Tsukuba Central 5, 1-1-1 Higashi, Tsukuba, Ibaraki 305-8565, Japan
}

(Received November 8, 2002; Accepted November 26, 2002)

\begin{abstract}
Based on our recent results, the present paper overviews noncovalent formation of high-axial-ratio nanostructures (HARNs), such as fibers, rods, tubes and ropes, through molecular self-assembly of bola-form amphiphilic (bolaamphiphilic) monomers. A variety of bolaamphiphiles, in which sugars, peptides, or nucleobases as headgroups are connected to both ends of a hydrocarbon spacer, were newly designed and synthesized. Their self-assembling behavior was examined in aqueous solutions in terms of bottom-up fabrication of organic nanostructures. The morphologies proved to strongly depend on the headgroup structure, spacer chain lengths and even-odd carbon numbers of used oligo(methylene) spacers. Typical examples of self-assembled morphologies include nanofibers from 1-glucosamide- or thymidine-appended bolaamphiphiles, vesicle-encapsulated microtubes from glycylglycine-appended bolaamphiphiles, double-helical ropes from thymine-appended bolaamphiphiles. These self-assembled HARNs are constructed hierarchically in a manner similar to biological structures. On the basis of several solid-state analyses, molecular packing and orientation within the HARNs are discussed and compared with the single crystal structures in terms of hydrogen-bond networks. Furthermore, pH-dependent reversible polymer formation was achieved using the combination of glucuronamideand aromatic boronic acid-appended bola-form derivatives. Polymerization of bola-form 1-glucosamide derivatives with a 1,4-butadiyne group was performed in self-assembled nanometer-sized fibers, giving a single polydiacetylene chain of 64-mer that can be seen in TEM.

KEY WORDS High-Axial-Ratio Nanostructure (HARN) / Bolaamphiphile / Self-Assembly / Noncovalent Synthesis / Hydrogen Bond / Nanofiber / Microtube / Nano-Rod / Rope / Hydrogel / Crystal Structure /
\end{abstract}

Biomaterials possess highly organized non-covalent structures formed spontaneously in bottom-up fashion, ${ }^{1}$ shaping natural body and functioning as energyconverting and information-converting materials. In contrast, conventional polymers are so-called linear macromolecules in which tens of thousands to millions of low-molecular-weight monomer units are connected to each other through covalent bonds. Very recently, a new family of polymers, including topologically complex polymers ${ }^{2-13,18-25}$ and self-assembled nanostructures, ${ }^{14-17,26}$ has attracted much attention. ${ }^{27,28}$ In particular, Kunitake and his co-worker built up the fundamental concept behind the polymolecular materials based on bilayer-containing molecular assemblies. ${ }^{29,30}$ Stupp et al.,,$^{31,32}$ Percec et al., ${ }^{33}$ and Whitesides et al. ${ }^{34,35}$ also succeeded in a molecule-up fabrication using polymer building blocks to realize nanometersized assemblies with well-defined shapes. The advantage of non-covalent self-assembly technique, unlike chemical reaction or polymerization, is in that it can directly produce ordered two- and three-dimensional structures like sheets, rods, fibers, tubes, disks, and spheres. It is more important that nanostructures can be constructed in high efficiency and accuracy and yet with minimum energy. ${ }^{36}$

We can find out a large number of fibrous structures such as collagen fibers, actin fibers, flagella in the size region of several tens to several hundreds nanometer. ${ }^{37}$ These natural fiber structures can be considered to be molecular self-assemblies of numerous poly(amino acid)s and proteins as building blocks. We then noticed that the biomaterials are forming highly ordered structures stabilized by threedimensional hydrogen bond network. ${ }^{38}$ Up to now there have been numerous studies on the construction of molecular complexes and assemblies using the directionality, complimenting nature, and cooperativity of the hydrogen bond. ${ }^{39,40}$ However, the point of discussion was on either hydrogen-bond formation in aprotic organic solvents or the control of hydrogenbond motif in gel, ${ }^{41-43}$ liquid crystalline, ${ }^{44,45}$ and crystalline states. ${ }^{46,47}$ The spontaneous formation of supramolecular structures having nanometer-sized and well-defined three-dimensional morphologies has been rarely achieved through hydrogen-bond formation in aqueous media. ${ }^{48-52}$ This is due to the fact that the enthalpy gain upon hydrogen bond formation between two molecules compensates well for the entropy 
loss accompanying the dissociation of bound water molecules. In other words, hydrogen bonding alone is not enough to stabilize the molecular complex in aqueous medium.

We then newly designed and synthesized bola-form amphiphiles ("bolaamphiphile") 53 carrying sugar, peptide, and nucleobase moieties with potential multiple hydrogen bond functionalities as a hydrophilic group at both ends, which are separated by linear oligo(methylene) spacer as a hydrophobic moiety. ${ }^{28}$ The linkage we mainly used between the hydrophobic and hydrophilic moieties is an amide linkage that is known to form a linear hydrogen bond chain. ${ }^{54,55}$ The stability of hydrogen bond networks is known to increase with increasing the hydrogen bond energy and the number of involved. Archaebacterial plasma membranes, existing in harsh environment, contain preferentially bolaamphiphilic compounds as constituents. Since they have two hydrophilic headgroups separated by one or two hydrophobic spacers, (i) they exhibit no polymorphism as compared to amphiphiles with a single head and a single tail, (ii) they can form relatively thinner monolayers than bilayer membranes, (iii) they can produce spherical vesicles by incorporating the unsymmetrical hydrophilic headgroups, and (iv) the membrane fusion common to usual bilayer membranes hardly takes place. ${ }^{53}$ These structural advantages of bolaamphiphilic monomers should increase the stability of the self-assembled membranes as compared to mono-head amphiphiles. By tuning the interlayer interaction based on the hydrogen bond networks between the hydrophilic headgroups, bolaamphiphiles can self-assemble to form supramolecular high-axialratio nanostructures including linear ribbons, helical ribbons, and tubular structures, depending on the molecular chirality, as shown in Figure 1.

\section{SUGAR-APPENDED BOLAAMPHIHILIC MONOMERS}

\section{Formation of Self-Assembled Supramolecular Fibers}

We have designed and synthesized sugar-based bolaamphiphiles 1(n), 2(n), and 3(n) (Scheme 1) in high yields, in which D-glucose, D-galactose, Dglucosamine, or D-glucuronic acid moiety is connected to both ends of oligo(methylene) chains of different lengths (C6 to $\mathrm{C} 20) .{ }^{56-58}$ The self-assembling behavior and the obtained morphologies were examined using confocal laser scanning, dark-field, polarized, and phase-contrast light microscopy. When saturated, hot aqueous solutions containing $\mathbf{1}(n)$ or $\mathbf{3}(n)$ were allowed to gradually cool and stand at room temperature, a variety of supramolecular fibers (nanofibers)

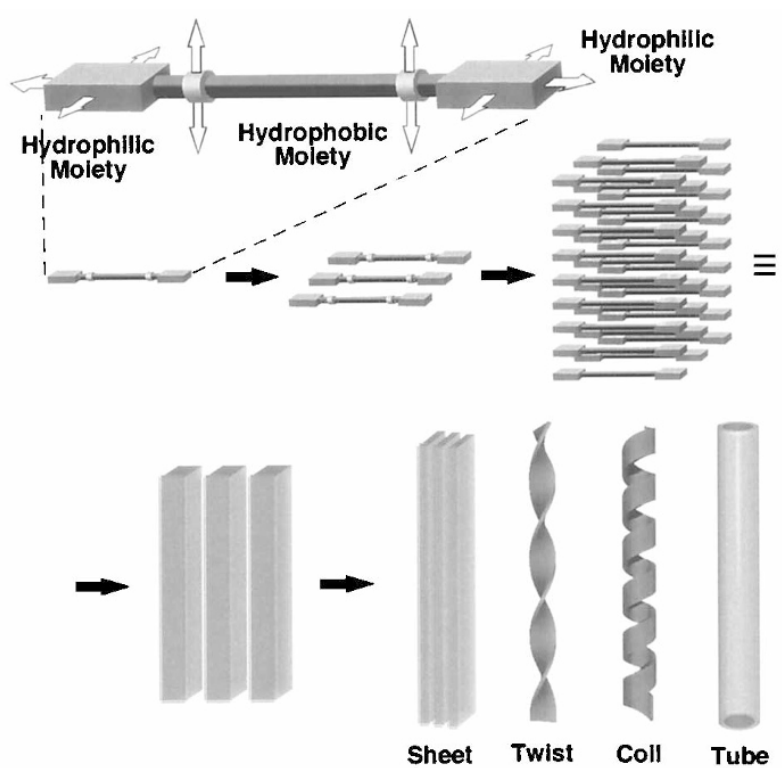

Figure 1. Schematic illustration for the bottom-up synthesis of high-axial-ratio nanostructures (HARNs) through molecular selfassembly of bolaamphiphilic monomers. Open arrows (upper figure) indicate hydrogen bond functionalities.

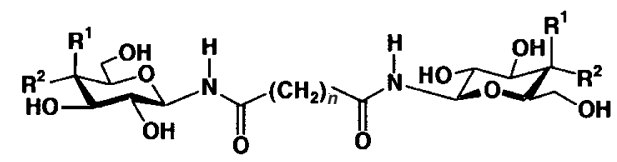

1(n): $\mathrm{R}^{1}=\mathrm{H}, \mathrm{R}^{2}=\mathrm{OH}(n=6-14,16,18$, and 20$)$

2(n): $\mathrm{R}^{1}=\mathrm{OH}, \mathrm{R}^{2}=\mathrm{H}(n=10,11$, and 12)

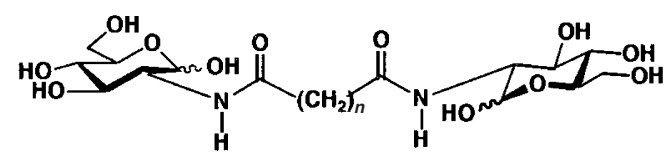

3(n): $(n=9,10,11,12,13,14,16$, and 18$)$<smiles>CCCNC(=O)CCCCCCCNC(=O)CCCC(=O)NCCCCCNC(=O)CCC</smiles><smiles>O=C(CCCCCC(=O)NCCCl)NCCCl</smiles>

Scheme 1.

with nanometer-sized dimension spontaneously and reproducibly appeared, strongly dependent on both the spacer length and the even/odd spacer carbon numbers (Figure 2). ${ }^{59,60}$ Interestingly, we found that physical properties and morphological stability of the obtained fibers are quite different from those of fibrous molecular assemblies made of synthetic bilayer-forming compounds. ${ }^{61-63}$ The obtained fibers are highly crystalline and thermally stable even at temperatures around $200^{\circ} \mathrm{C}$ after dehydration, proving that they can be isolated from the solution. The bolaamphiphile 1(10) was 

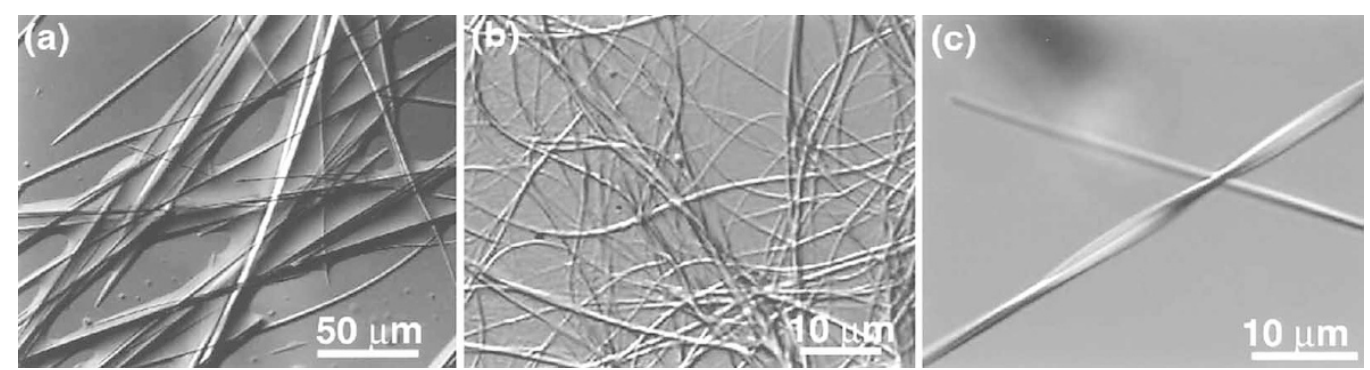

Figure 2. Self-assembled fibers made of (a) 1(6), (b) 1(10), and (c) 1(12) observed using confocal laser scanning microscopy (in water at $25^{\circ} \mathrm{C}$ )

Table I. Representative self-assembled morphologies from sugar-appended amphiphilic monomers

\begin{tabular}{|c|c|c|c|c|c|}
\hline Amphiphile & $\begin{array}{l}\text { Self-assembled } \\
\text { morphology }\end{array}$ & Solvent & Width (nm) & Length $(\mu \mathrm{m})$ & Ref \\
\hline 1(8), 1(10), 1(12) & Helical fiber & water & $30-3000$ & ca. 1000 & 60 \\
\hline $1(9), 1(13)$ & Amorphous solid & water & n.d. ${ }^{\mathrm{a}}$ & n.d. ${ }^{\mathrm{a}}$ & 60 \\
\hline 1(11) & Platelet & water & $3 \times 10^{5}$ & ca. 800 & 60,74 \\
\hline $2(10), 2(12)$ & Needle crystal & water & ca. $5 \times 10^{4}$ & ca. 90 & 66 \\
\hline 3(10), 3(12), 3(14) & Helical fiber & water/ethanol $(1 / 1)$ & $8-25$ & ca. 20 & 57 \\
\hline 3(11), 3(13) & Thin ribbon, sheet & water/ethanol (1/1) & $10-150$ & ca. 20 & 57 \\
\hline $6(9), 6(10), 6(11)$ & Helical fiber & water & $30-100$ & ca. 1000 & u.p. ${ }^{b}$ \\
\hline 8 & Nanofiber & ethyl acetate/ $n$-hexane $(3 / 7)$ & $6-30$ & n.d. ${ }^{\mathrm{a}}$ & 86 \\
\hline 10 & Nanofiber and ribbon & water/THF (1/9) & $50-300$ & n.d. ${ }^{a}$ & 87 \\
\hline
\end{tabular}

${ }^{a}$ Not determined. ${ }^{b}$ Unpublished.

found to self-assemble into flexible nanofibers of less than $100 \mathrm{~nm}$ in diameter, several hundreds micrometers in length. Rapid cooling of the hot aqueous solutions of 1(10) induced typical gelation. The obtained gel can be turned upside down without any flow. Furthermore, the longer derivative 1(12) produced helically coiled right-handed ribbon structures through molecular selfassembly. The obtained helical pitches of $200 \mathrm{~nm}-$ $10 \mu \mathrm{m}$ and width of $10 \mathrm{~nm}-3 \mu \mathrm{m}$ were randomly distributed. The self-assembling behavior and typical morphologies produced from $\mathbf{1}(n), \mathbf{2}(n)$, and $\mathbf{3}(n)$ are summarized in Table I.

\section{Molecular Arrangement in Self-Assembled Fibers and Even/Odd Effect of Oligo(methylene) Spacer}

In the nanometer-sized fiber formation through molecular self-assembly, we realized that only evennumbered bolaamphiphiles 1(6), 1(10), 1(12), and 1(14) produce fibrous assemblies whereas the odd numbered homologues gave amorphous solids with 1(9) and 1(13) or a platelet crystal with 1(11). ${ }^{60}$ To date it has been well documented that enantiomeric amphiphiles self-assemble into mirror-imaged molecular assemblies and the racemic mixtures non-chiral planar platelet ribbon morphologies. ${ }^{48,49,63,64}$ Thus, the present finding gives the first example of the stereochemical effect of even- and odd-numbered oligo(methylene) chains on the self-assembled fiber morphologies.

From the comparison of the molecular packing of odd-numbered 1(11) in a single crystal with that of even-numbered galactose homologues $2(\mathbf{1 0})^{65}$ and 2(12), ${ }^{66}$ we found a remarkable difference in the stacking motif of the layer structure (see next section). This structural feature can be designated as so-called "polytypes" ${ }^{67-69}$ and should also occur for the present assembly from the odd- and even-numbered bolaamphiphiles. Figure 3 illustrates schematically a "polytype" observed for the molecular packing in the crystal structure of odd-numbered 1(11) and even-numbered 2(12). The odd-numbered bolaamphiphile forms a pleated sheet arrangement of the layer, whereas the even-numbered homologue a parallel sheet packing. It also should be noted here that the relative orientation of the amide carbonyl groups is the same within both each molecule and each layer for 1(11) whereas we found antiparallel orientation of the amide functionalities within each molecule for 2(12) ${ }^{60}$ Thus, we collected several pieces of evidence to depict a possible self-assembling model based on the monolayered sheet structure within a unit fiber from 1(12) (Figure 4). The bolaamphiphiles pack side by side to form the monolayer sheet of $2.45 \mathrm{~nm}$ long-range spacing. In addition, the bolaamphiphilic molecules are tilting their oligo(methylene) chains by $45-50^{\circ}$ with respect to the monolayer plane normal.

The $\mathrm{CH}_{2}$ antisymmetric $v_{\mathrm{as}}\left(\mathrm{CH}_{2}\right)$ and symmetric $v_{\mathrm{S}}\left(\mathrm{CH}_{2}\right)$ stretching vibration frequencies are known to reflect sensitively a gauche/trans population in 
(a)

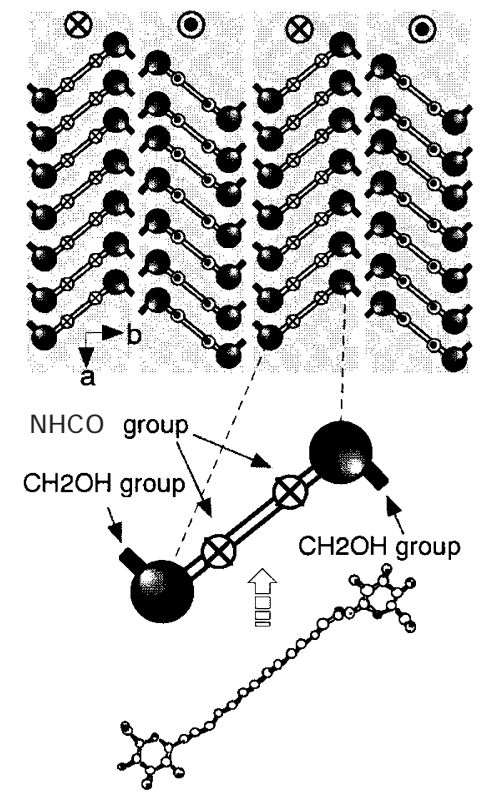

(b)
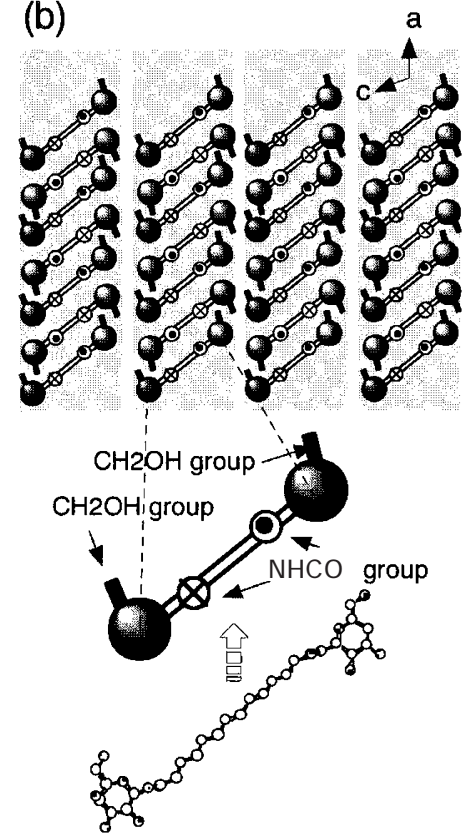

Figure 3. Schematic illustration of a "polytype", that means the difference in the stacking motif of monolayers between 1(11) (left) and 2(12) (right). The amide hydrogen bond chains run roughly along the $c$-axis. The symbols $(\otimes)$ and $(\bullet)$ represent the amide groups in which the carbonyl oxygen atom is placed below and above the plane, respectively.

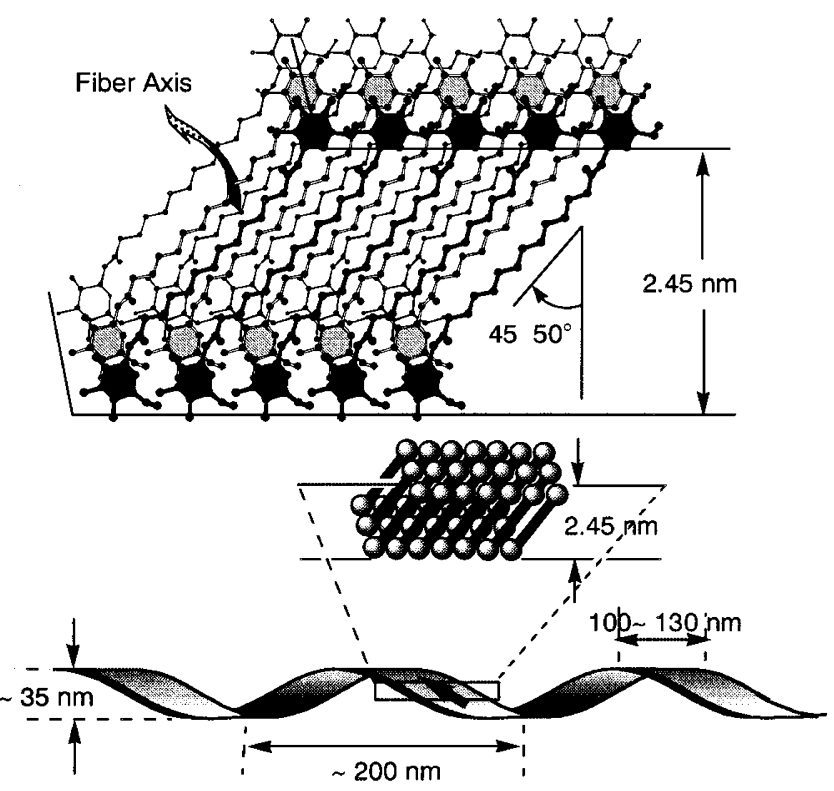

Figure 4. A possible self-assembling model for the solid monolayer sheet of $\mathbf{1 ( 1 2 )}$ in a unit fiber. The parallel stacking motif of this layer structure will allow the self-assembled fibers to be helically coiled as the expression of the molecular chirality at supramolecular level.

the oligo(methylene) chain. The dependence of both stretching vibration bands of $\mathbf{1}(\boldsymbol{n})$ on the oligo(methylene) spacer length indicated a gaucheincluding conformation for the relatively shorter-chain homologues $(6 \leq n \leq 8$, and $n=10)$ and an all-trans conformation for the medium- $(n=9$, and $11 \leq n \leq 13)$ and long-chain derivatives $(14 \leq n \leq 20)$ (Figure 5a). Furthermore, the band frequencies of the amide I and (a)
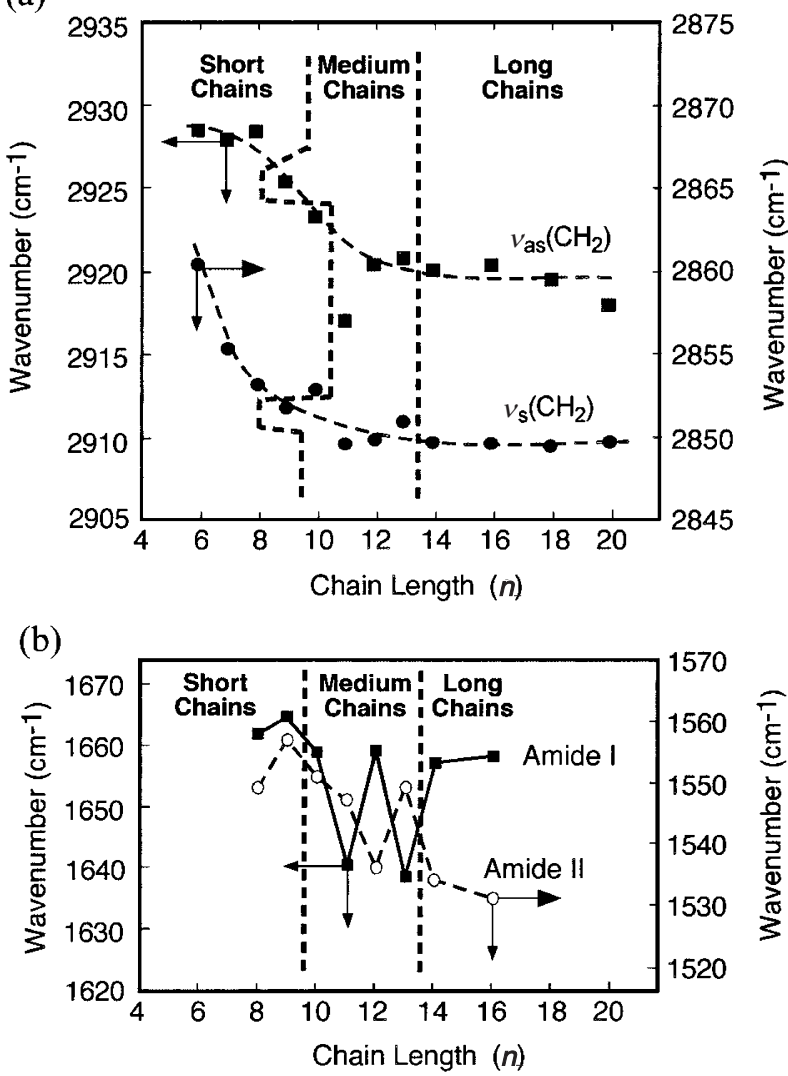

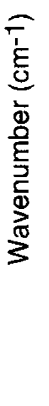

Figure 5. The dependence of (a) the $v_{\mathrm{as}}\left(\mathrm{CH}_{2}\right)$ and $v_{\mathrm{s}}\left(\mathrm{CH}_{2}\right)$ band frequencies and (b) the amide I and II band frequencies on the oligo(methylene) spacer length $(n)$ for the self-assembled $\mathbf{1}(\boldsymbol{n})$.

II bands clearly show an even/odd effect for the chain length $n(n \geq 10)$, as shown in Figure 5b. Similar kinds of even/odd effect on the amide I and II adsorp- 
tion bands can also be seen upon the nanofiber formation from 2-glucosamide homologues $\mathbf{3}(n)^{57}$ or diamide bolaamphiphiles, ${ }^{70}$ as well as for the cast films of azobenzene-containing amphiphiles..$^{71,72}$

Powder X-Ray diffraction (XRD) patterns of the selfassembled 1(n) displayed different types of diagrams in the wide-angle region, depending on the even/odd numbers of the oligo(methylene) chains.$^{60}$ Consequently, the subcell structure in $\mathbf{1}(\boldsymbol{n})$ is found to show an orthorhombic $\left(\mathrm{O}_{\perp}\right)$ or monoclinic $\left(\mathrm{M}_{\|}\right)$packing of the oligo(methylene) chain for $n=6,12,14$, and a triclinic $\left(\mathrm{T}_{\|}\right)$packing for $n=9$ and 11. The band frequencies and profile of the $\mathrm{CH}_{2}$ scissoring and rocking vibration also supported this assignment of the subcell structure, showing the even/odd effect. Long-range ordering observed using small angle XRD also featured the similar difference in even- and odd-numbered bolaamphiphiles. Considering all findings and evidences, we can assume that the difference in polytype structure mainly drives the observed even/odd effect on the selfassembled fiber morphologies.

\section{Molecular Packing in the Single Crystal}

Odd-numbered amphiphile 1(11) gave the first example of single crystal structure for aldopyranoseappended bolaamphiphiles. The molecules 1(11) form a pleated sheet structure in the crystalline state, in which the undecamethylene chains are tilted by approximately $49^{\circ}$ to the normal of the bilayer plane (Figure 6).$^{73,74}$ It should be noted here that 24 hydrogen bonds per molecule proved to participate in the stabilization of the self-assembled crystal structure. The linear molecular array of 1(11) along the $b$-axis should be comparable to that of nylon-77 (4) $)^{75}$ since the nylon-77 can be considered as a bola-form compounds in which two long polyamide chains are linked to both ends of 1,5-pentadicarboxylic acid. The molecule 1(11) takes a linear alignment through the hydrogen bond linkage and then forms a self-assembled quasi-polymer chain that is similar to that of the common polyamide chain. In marked contrast, bis(glutaramide) (5) having any hydrogen-bond functionalities at both ends takes a random molecular orientation that cannot be constrained by the terminal functional groups. ${ }^{76}$

All the single crystal analysis of mono-head carbohydrate amphiphiles ${ }^{77}$ determined so far shows the formation of incomplete bilayer structure, including interdigitated alkylene chain packing without exception. ${ }^{78}$ The reason for this feature is that the molecular shape of each carbohydrate amphiphile is characterized by a bulky pyranose headgroup. Therefore, no one can envisage such stable nanofiber formation from bolaamphiphilic molecules with a glucopyranose headgroup

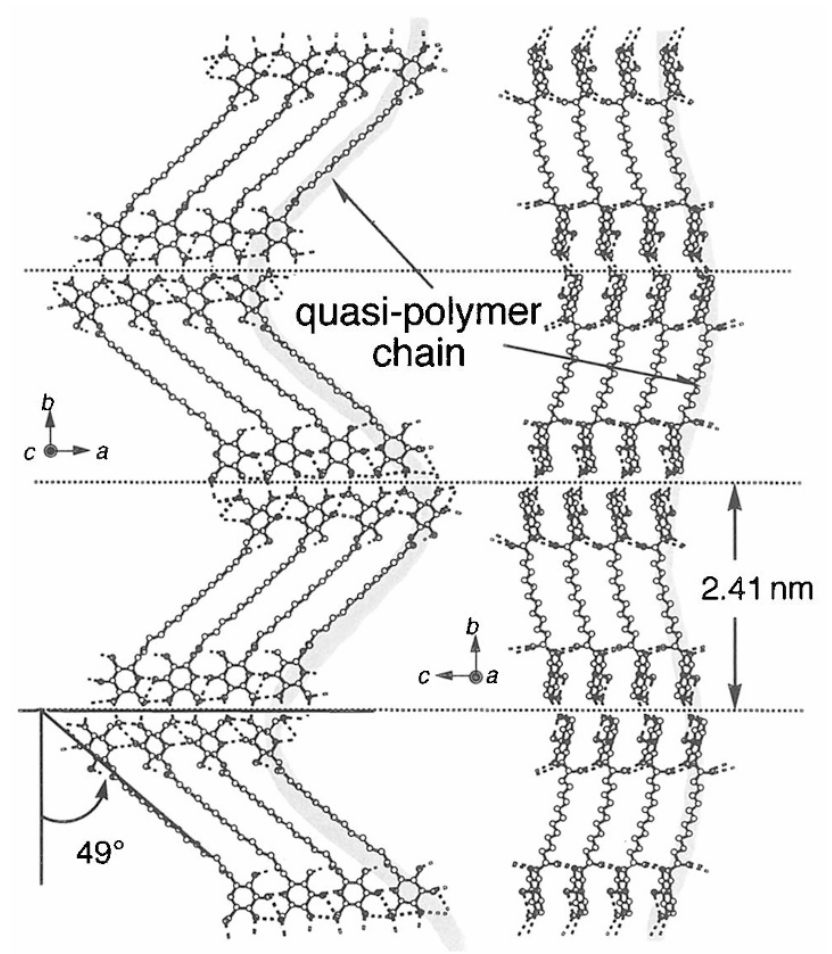

Figure 6. X-Ray single crystal structure of 1(11) viewed along the $c$ - (left) and the $a$-axis (right). Hydrogen bond networks are denoted. A gray linear band shows one-dimensional polymolecular chain formed by hydrogen bonding.

separated by oligo(methylene) spacers.

We also found that the constraining hydrogen bond networks can allow the oligo(methylene) chain to enforce conformational deviation from the extended form. ${ }^{79}$ The crystalline character of the obtained selfassembled fibers allows us to analyze the molecular arrangement within the fibers using infrared spectroscopy (FT-IR), powder XRD and differential scanning calorimetry (DSC). We were able to classify the behavior of the oligo(methylene) spacer into three categories, short $(6 \leq n \leq 8$, and $n=10)$, medium ( $n=$ 9 , and $11 \leq n \leq 13)$, and long chain $(14 \leq n \leq$ 20). ${ }^{79}$ The 1-glucosamide bolaamphiphiles $\mathbf{1}(\boldsymbol{n})$ with a short chain oligo(methylene) spacer were found to selfassemble in water to form a gauche-including multiple monolayer self-assemblies, whereas the medium- and long-chain bolaamphiphiles showed polymorphism on heating, which proceeded with retention of the gauche chain conformation (Figure 7). Interestingly, the 1(n) homologues with long-chain spacers transformed from the $\mathrm{K} 1$ crystalline phase into the $\mathrm{K} 2$ crystalline phase with keeping an all-trans conformation, and eventually to the $\mathrm{K} 3$ crystalline phase with a gauche-including oligo(methylene) spacer. Furthermore, it should be noted here that the long-chain derivatives $\mathbf{1}(n)(n=14$, 16,18 , and 20) and the medium-chain 1(13) formed a thermotropic mesophase (smectic A). ${ }^{79}$ 


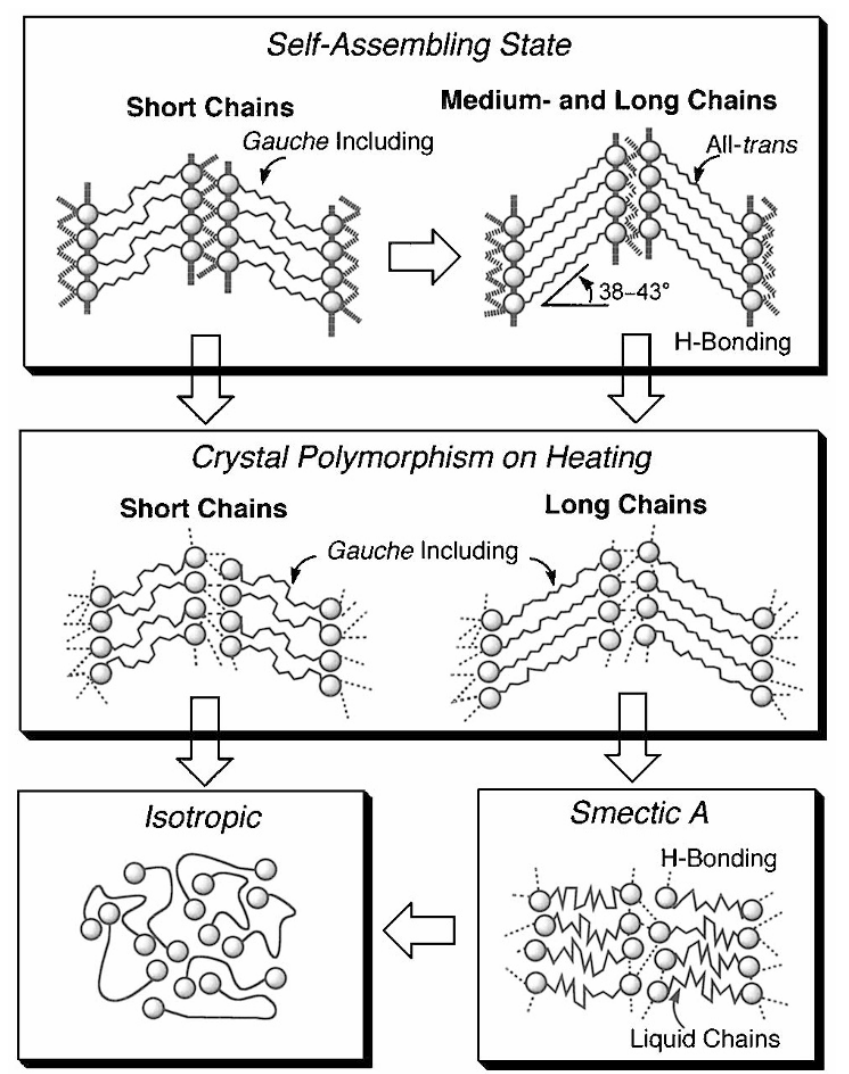

Figure 7. Schematic illustration of conformational changes in the oligo(methylene) spacers of the self-assembled $1(n)$ upon heating.

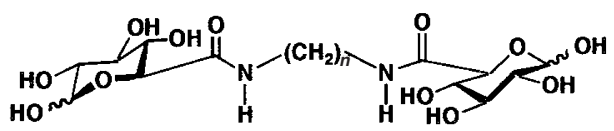

6(n): $(n=9,10,11,12,13,14,16$, and 18)

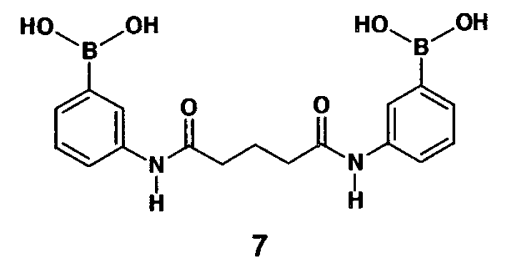

Scheme 2.

\section{pH-DEPENDENT REVERSIBLE POLYMER FORMATION FROM BOLA-FORM DERIVATIVES}

Glucuronamide-appended bolaamphiphiles 6(n) $(n=$ $9,10,11,12,13,14,16$, and 18) (Scheme 2) proved to form a reversible, linear polymolecular array in aqueous solutions upon complexation with aromatic boronic acid-appended homologue $7 .^{58}$ Of particular note is that the reversible polymer formation and dissociation were achieved depending on $\mathrm{pH}$ conditions of the aqueous solutions used.
Aromatic boronic acids are known to form specific complexes with cis-diol-type hydroxyl groups of carbohydrates via ester-linkage formation. ${ }^{81-83}$ Mikami and Shinkai first achieved the synthesis of main-chain sugar-containing polymers through self-condensation with diboronic acid under nonaqueous conditions. ${ }^{84,85}$ Based on our continued interest in sugar-based bolaamphiphiles, we have newly synthesized glucuronamideappended bolaamphiphiles $\mathbf{6}(\boldsymbol{n})$ possessing free 1,2diols available for ester formation with a bola-form aromatic boronic acid derivative. In order to confirm linear complex formation between the glucuronamideand boronic acid-appended bola-form derivatives, we employed ${ }^{11} \mathrm{~B}$ NMR spectroscopy since it is very sensitive to the spin state of the boron atom, such as neutral $\mathrm{sp}^{2}$, anionic $\mathrm{sp}^{3}$, and coordinated $\mathrm{sp}^{3}$ states. Actually, the ${ }^{11} \mathrm{~B}$ NMR spectra of the boronic acid derivative 7 displayed that the complexation with the glucuronamide derivative $\mathbf{6 ( 1 2 )}$ produces covalently attached $\mathrm{sp}^{3}$ hybridization to give a polymolecular chain (ca. 70\%) equilibrated with a small amount of free anions (ca. 30\%) (Figure 8). Multiangle laser light scattering (MALLS) analysis for the present aqueous 6(12)/7 polymer showed weight-averaged molecular weight $\left(M_{\mathrm{w}}\right)$ of $2.04 \times 10^{6} \mathrm{~g} \mathrm{~mol}^{-1}$ at $\mathrm{pD} 10.8$. The decrease in the $\mathrm{pH}$ value of the aqueous solution from 11 to 3 resulted in a down-field shift of the main signal from $\delta=-11$ to $11 \mathrm{ppm}$, showing the complete dissociation of the polymer. As illustrated in Figure 9, the gulucuronamide-based condensation polymer can thus be "turned" on and off by tuning the $\mathrm{pH}$ of the aqueous polymerization medium.

\section{SELF-ASSEMBLY AND SUBSEQUENT POLYMERIZATION OF BOLA-FORM MONOMERS IN NANOMETER-SIZED FIBERS}

In order to achieve topochemical polymerization within nanometer-sized self-assembled fiber matrix, we introduced polymerizable 1,4-butadiynes into an oligo(methylene) spacer of the sugar-based bolaamphiphiles $\mathbf{1}(\boldsymbol{n})$ and $\mathbf{2 ( n )}$ (see, 8, 9, and $\mathbf{1 0}$ in Scheme 3). ${ }^{86}$ Thus, we succeeded in obtaining covalently linked polydiacetylenic nanometer-sized fibers by the combination of the self-assembly into nanofiber morphologies and subsequent polymerization within the nanofibers. ${ }^{87}$ The polymerization scheme using a nanofiber matrix is schematically shown in Figure 10. Polymerization of constituent polymerizable molecules in supramolecular assemblies resulted in stable covalent assemblies. Only few studies have been reported for the polymerization using monolayer lipid membranes (MLMs) of diacetylene derivatives as a matrix, 


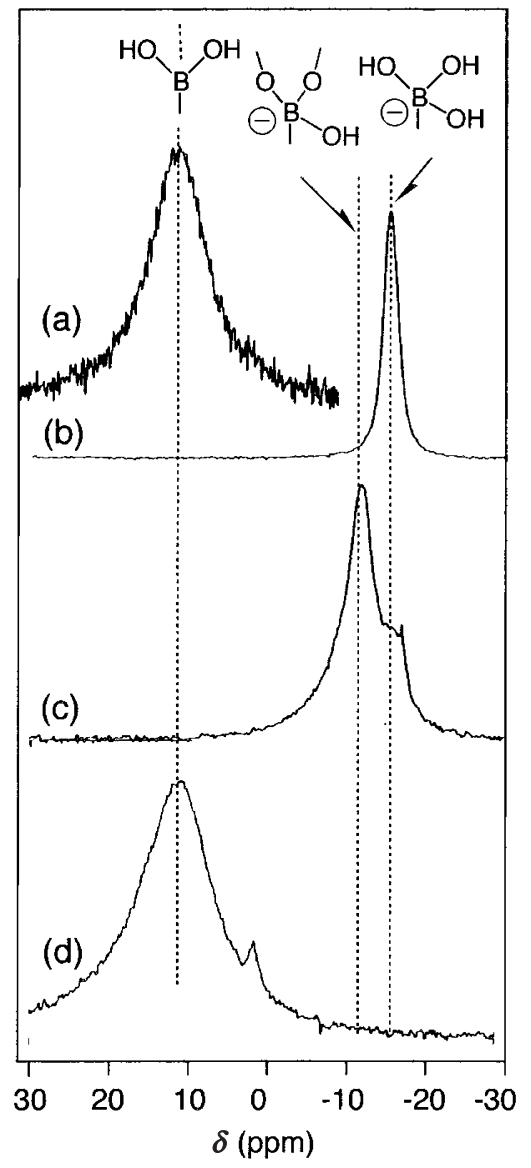

Figure 8. ${ }^{11} \mathrm{~B}$ NMR spectral change of the monomer 6(12) upon complexation with $7\left[0.1 \mathrm{M}\right.$, at $25^{\circ} \mathrm{C}$ in $\mathrm{D}_{2} \mathrm{O} /$ methanol- $d_{4}$ $(6: 4, \mathrm{v} / \mathrm{v})]$. (a) 7 under weak acidic aqueous condition $(\mathrm{pD}=3.0)$; (b) 7 under alkaline aqueous condition $(\mathrm{pD}=12.7)$; (c) a $1: 1$ mixture of $6(12)$ and $7(\mathrm{pD}=10.9)$; and $(\mathrm{d})$ a $1: 1$ mixture of $6(\mathbf{1 2})$ and $7(\mathrm{pD}=3.0)$. such as liposomes ${ }^{88}$ or multi-layer sheets, ${ }^{89,90}$ which highly contrasts to a number of studies on the bilayermembrane (BLM)-templated polymerization. ${ }^{91-97}$ Furthermore, the molecular weights of the polydiacetylne products have been uncertain due to the fairly poor solubility of the polymerized entity. Unidirectional selfassembly along the molecular short axis and subsequent polymerization enabled us to obtain isolated, single poly(diacetylene) chains. Favorably, the packing parameters of the alkylene chains in the single crystal of 1-glucosamide and 1-galactosamide bolaamphiphiles 1(10), 2(10), and 2(12) are found to be in good agreement with those of well-known, reactive diacetylene monomers. ${ }^{65,66,73,74,98}$

Polymerizable bolaamphiphile with a butadiyne moiety $\mathbf{8}$ can gelatinize a mixture of ethyl acetate and $n$-hexane $(4 / 1, \mathrm{v} / \mathrm{v})$ to form an organogel consisting of nanofibers of $5-20 \mathrm{~nm}$ widths, as shown in Fig-
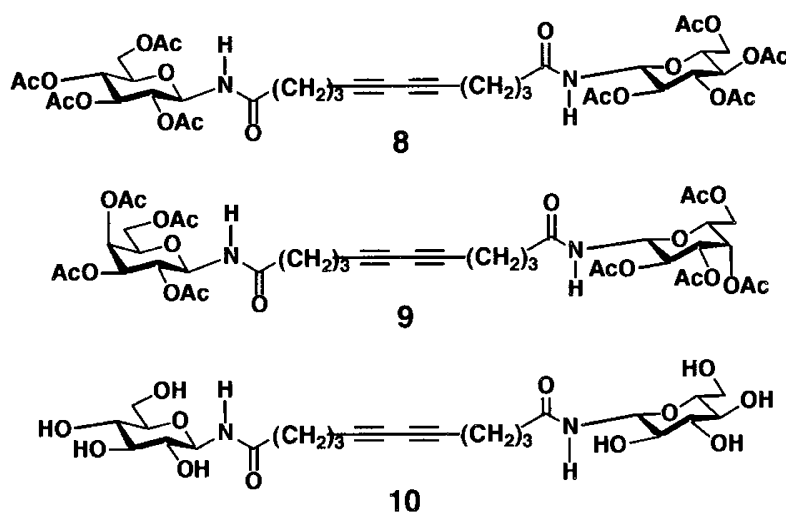

Scheme 3.

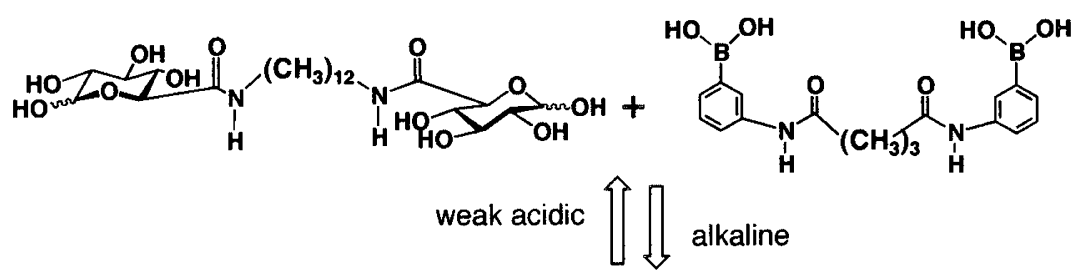

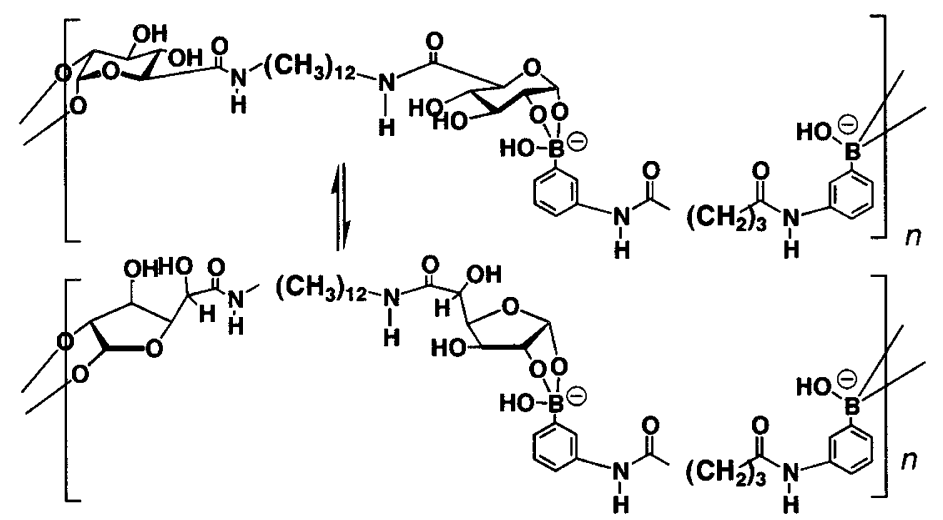

Figure 9. Possible structures of the polymer main chain formed from the mixture of the glucuronamide- 6(12) and aromatic boronic acid-based bolaamphiphilic monomers 7 . 


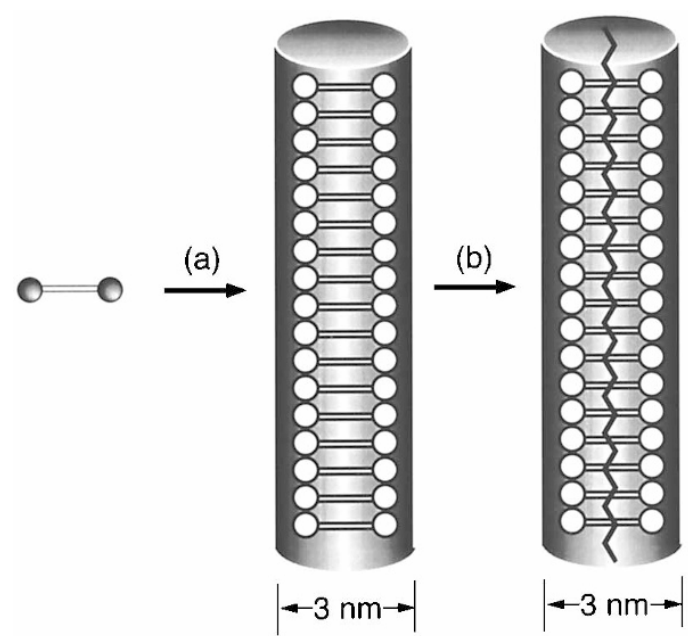

Figure 10. Polymerization scheme of bola-form butadiyne 1glucosamide 8, consisting of (a) the self-assembly into single nanofiber morphology and (b) the subsequent polymerization in the nanofiber as a matrix.

ure 11a. The galactosamide homologues 9 gave no gel structures from common organic solvents such as $\mathrm{MeOH}, \mathrm{CHCl}_{3}$, and $N, N$-dimethylformamide. The fibrous gel of $\mathbf{8}$ in the mixture of ethyl acetate $/ n$ hexane changed the color from colorless to red $\left(\lambda_{\max }=\right.$ 506 and $546 \mathrm{~nm}$ ) upon exposure to $254 \mathrm{~nm}$ UV light. This finding corresponds to a blue-shifted UV absorption maxim in comparison with those for solidstate-polymerized poly(diacetylene)s and shows good consistency with that of poly(5,7-dodecadiyne-1,12diol-bis $\{[(4-b u t o x y c a r b o n y l) m e t h y l] m e t h a n e\})$ (poly4BCMU) characterized by $\lambda_{\max }=494$ and $530 \mathrm{~nm}$ at $56^{\circ} \mathrm{C}$ in toluene. ${ }^{99,100} \mathrm{FT}$-IR spectroscopy can support that the ladder structure stabilized linear amide hydrogen bond chains is crucial for the present topochemical polymerization. Actually, dried amorphous solids of $\mathbf{8}$, derived from chloroform solution, gave no drastic color change based on the extension of the $\pi$-conjugate. The UV-polymerized nanofibers were found to be insoluble in toluene that can solubilize monomer species, but were still soluble in chloroform. Therefore, we performed gel permeation chromatography (GPC) of the polymerized nanofibers using chloroform as an eluent and found the existence of a peak maximum at $M_{\mathrm{n}}=1.1 \times 10^{4}$ corresponding to a 13-mer (Figure 12a). High-resolution energy-filtering transmission electron microscopy (EF-TEM) revealed that the minimum width of the polymerized nanofibers was $c a$. 3$\mathrm{nm}$ corresponding to an extended molecular length of 8. This also means that we are showing an example of a direct TEM observation of an isolated or bundles of oligodiacetylene-containing chain(s) (Figures 11a and 11b).

On the other hand, deacetylated bolaamphiphilic
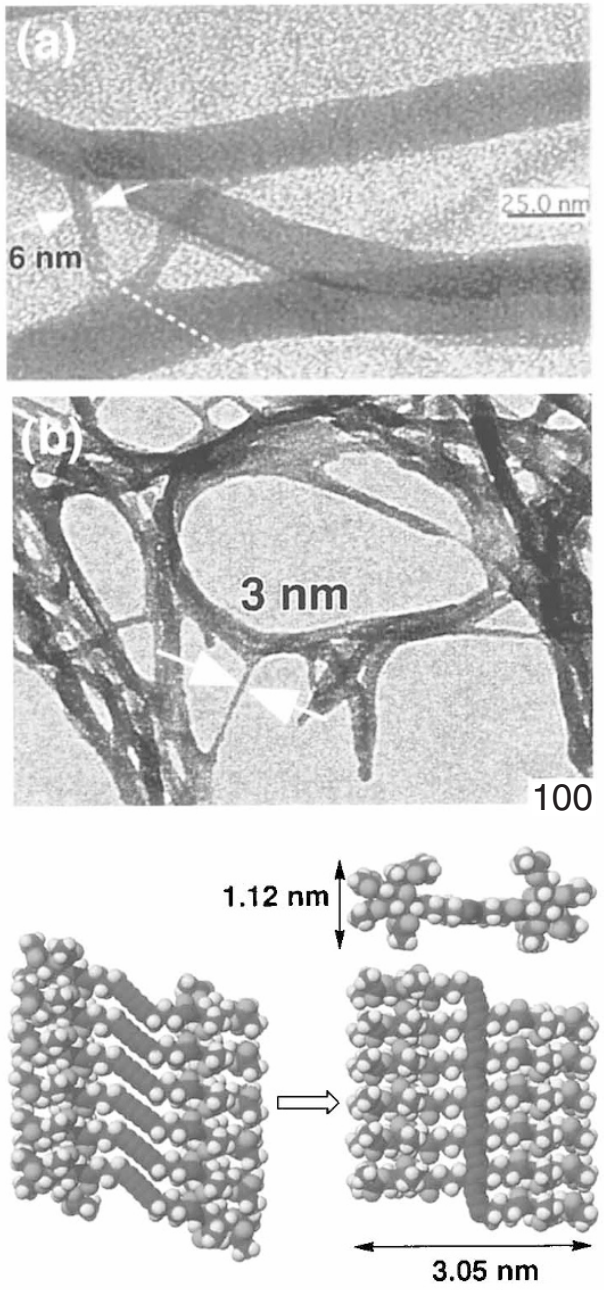

(a)

(b)

Figure 11. EF-TEM images of (a) self-assembled (unpolymerized) nanofibers made of $\mathbf{8}$ and (b) $\gamma$-ray-irradiated (polymerized) fibers of 8. Corresponding self-assembled structure in the single nanofiber and the resultant polymer chain structure were shown using CPK molecular model.

derivative $\mathbf{1 0}$ also gelatinized a mixture of water and tetrahydrofuran (THF) to result in a gel structure consisting of a number of nanofibers. ${ }^{87}$ TEM observation showed that the obtained fibrous assemblies are fiber- or ribbon-shaped sheets with a minimum width of $50 \mathrm{~nm}$, much larger than those obtained for fibers from $8(6 \mathrm{~nm})$. The UV polymerization for the fibrous assemblies from $\mathbf{1 0}$ resulted into the production of polydiacetylenic nanostructures with relatively higher molecular weights of 64-mer (Figure 12b) since the amide and sugar hydroxyl groups in $\mathbf{1 0}$ will allow the formation of stronger, multiple hydrogen bond networks within the gel nanofibers as compared to the case of 8. These polydiacetylenic nanofibers and nanoribbons can be applicable as conducting molecular wires and ribbons in that the nanometer-sized fibers consist of both conducting $\pi$-conjugated moieties in the cen- 


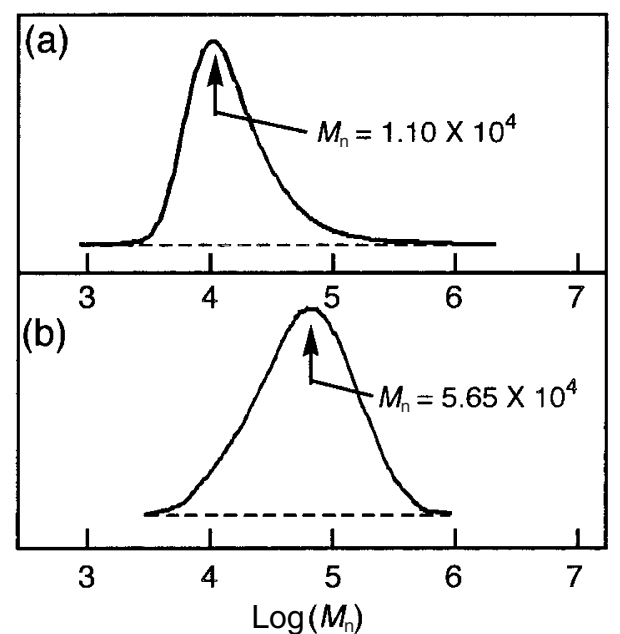

Figure 12. Molecular weight distribution of the UVpolymerized nanofibers evaluated against a polystyrene standard: (a) the GPC profile of the polymerized $\mathbf{8}$ after 40-min irradiation for 8 in EtOAc/n-hexane $(1: 9, \mathrm{v} / \mathrm{v})$ and (b) the GPC profile of the subusequently peracetylated $\mathbf{1 0}$ after 10 -min irradiation in $\mathrm{H}_{2} \mathrm{O} / \mathrm{THF}(1: 9, \mathrm{v} / \mathrm{v})$. Absorbance was monitored at $462 \mathrm{~nm}$. Eluent: $\mathrm{CHCl}_{3}$.

tral part and acetylated sugar units as an insulating layer. The present self-assembly approach also provides a more facile preparation for an isolated molecular wire as compared to recently developed, interesting $\pi$-conjugated long molecules. ${ }^{101-103}$

\section{OLIGOPEPTIDE-APPENDED BOLAAMPHIPHILIC MONOMERS}

\section{Formation of Vesicle-Encapsulated Microtubes}

We incorporated an oligopeptide moiety instead of the aforementioned sugar headgroup into a hydrophilic group of bolaamphiphiles. Thus, $C$ terminated oligopeptide-based bolaamphiphiles 11(n)16 were designed and synthesized, in which an oligoglycine, oligosarcosine, oligo(L-proline), glycylsarcosylsarcosine, or glycyl-L-prolyl-L-proline moiety is connected to both ends of the $\alpha, \omega$-long-chain dicarboxylic acid (Scheme 4). ${ }^{104}$ Bolaamphiphiles with a glycylglycine residue as a hydrophilic headgroup selfassembled in weak alkaline aqueous solutions into unprecedented, few micrometer-sized tubular structures with high-aspect ratios and closed ends. ${ }^{105}$ Several light microscopic studies revealed that the microtubes encapsulate a number of spherical assemblies inside the tubular structures (Figure 13). In particular, phase-contrast light microscopy indicated that the encapsulated assemblies are neither oil droplets nor air bubbles, but multilamellar vesicles (Figure 13b). Surprisingly, the tubular morphologies were very stable and remained intact even after sonication or heating of the aqueous disper-

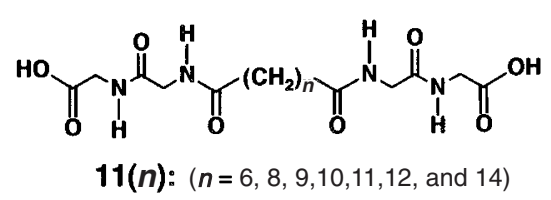

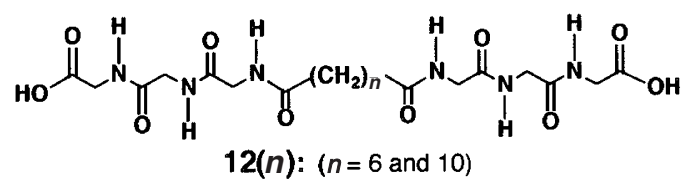<smiles>CN(CC(=O)N(C)CC(=O)N(C)C(=O)CCC(=O)N(C)CC(=O)O)C(=O)O</smiles><smiles>O=C(O)C1CCN(C(=O)CCC(=O)N2CCCN2C(=O)CCC(=O)N2CCCC2C(=O)O)C1=O</smiles>

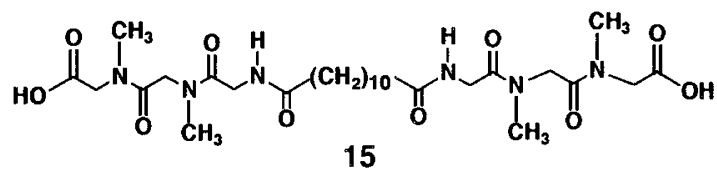<smiles>O=C(CCC(=O)N1CCCC1C(=O)O)NC(=O)CN1CCCC1C(=O)NCC(=O)N1CCCC1C(=O)O</smiles>

Scheme 4.

sions up to $90^{\circ} \mathrm{C}$. Furthermore, dehydration and subsequent drying in vacuum induced no morphological change of the microtubes (Figure 13c). The addition of excess of water to the dried microtubes regenerated the vesicle-encapsulated microtubes through effective hydration by sonication.

The present findings imply that once hydrogenbond networks were formed in the self-assemblies of the glycylglycine-appended bolaamphiphiles, the well-defined tubular nanostructures are physically and thermally very stable. Both the glycylglycine residue in oligopeptide headgroup and appropriate lengths of even-numbered oligo(methylene) spacers are indispensable for the microtube formation. ${ }^{104}$ Table II summarizes the self-assembled morphologies from a series of oligopeptide-appended bolaamphiphiles. The bolaamphiphiles lacking glycylglycine or glycylglycylglycine residues in the headgroup produce no microtubular structures through self-assembly. Poly(glycine) (Nylon-2) is known to form a hexagonal array [poly(glycine) II-type structure] with amide hydrogen-bond-gliding even $120^{\circ} .107$ This structural feature highly contrasts to the fact that aliphatic polyamides always form a parallel sheet structure through the formation of two-dimensional hydrogen bonds (Figure 14). ${ }^{106,108}$ Thus, the gly- 


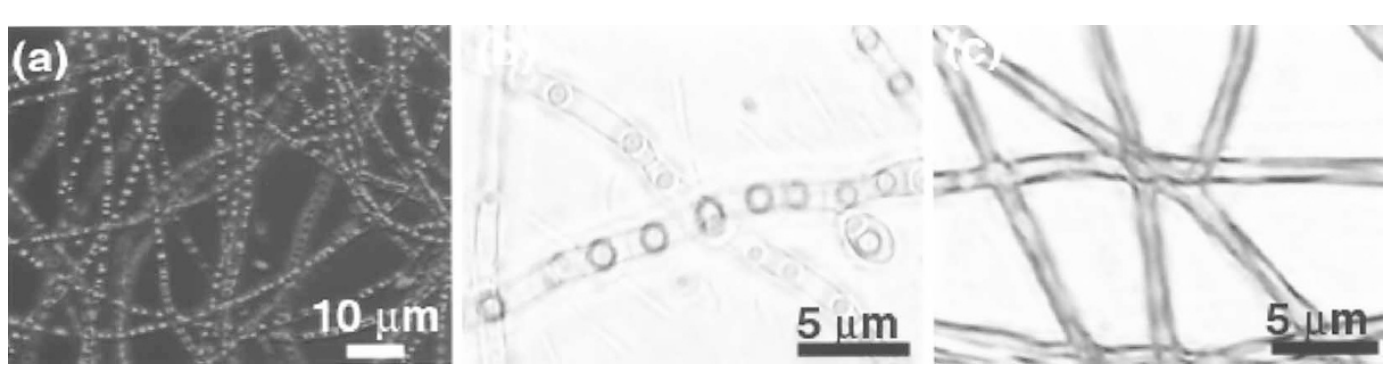

Figure 13. Vesicle-encapsulated microtubes from 11(10) observed using phase-contrast light microscopy. (a) and (b): in water at $25^{\circ} \mathrm{C}$ (left and middle) and (c): after vacuum drying (right).

Table II. Representative self-assembled morphologies from oligopeptide-appended bolaamphiphilic monomers

\begin{tabular}{|c|c|c|c|c|c|}
\hline Amphiphile & $\begin{array}{l}\text { Self-assembled } \\
\text { morphology }\end{array}$ & Solvent & Width (nm) & Length $(\mu \mathrm{m})$ & Ref \\
\hline $11(6), 11(8), 11(10)$ & Microtube & water $(\mathrm{pH} 7-10)$ & $1000-3000$ & ca. 1000 & 105 \\
\hline $11(6), 11(8), 11(10)$ & Vesicle & water $(\mathrm{pH} 7-10)$ & $100-3000$ & $0.1-3$ & 104 \\
\hline $11(10)$ & Rod-like micelle & water $(\mathrm{pH} 7-10)$ & 10 & $0.05-0.3$ & 104 \\
\hline 11(10) & Needle & water $(\mathrm{pH} 7-10)$ & $20-50$ & $2-10$ & 105,113 \\
\hline $12(6), 12(10)$ & Microtube & water $(\mathrm{pH} 7-10)$ & ca. 1000 & ca. 1000 & 104 \\
\hline $13,14,15,16$ & Solution & water $(\mathrm{pH} 7-10)$ & n.d. ${ }^{\mathrm{a}}$ & n.d. ${ }^{\mathrm{a}}$ & 104 \\
\hline $17(n)(n \geq 7)$ & Nanofiber & water $(\mathrm{pH} \mathrm{7-10)}$ & $10-15$ & ca. 10 & 124 \\
\hline $18(8)$ & Ribbon & water (pH 5-6) & $10^{3}-10^{5}$ & ca. 1000 & 125 \\
\hline $19(8), 19(10), 19(12)$ & Nanofiber & water (pH 5-6) & $10-15$ & ca. 10 & 125 \\
\hline
\end{tabular}

${ }^{\text {a }}$ Not determined.

(a)

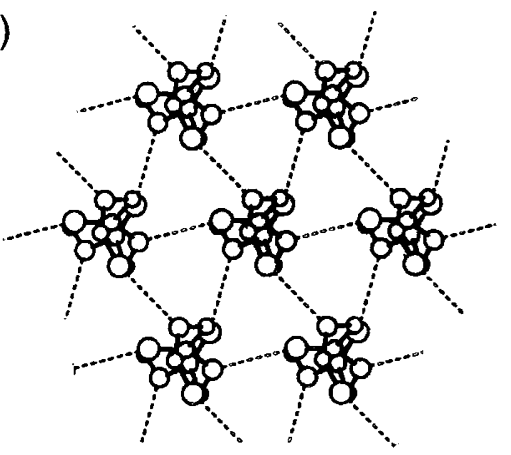

(b)

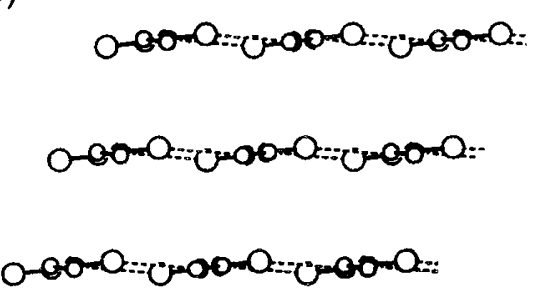

Figure 14. Molecular packing in (a) the polyglycine II structure by Nylon-2 (polyglycine), and (b) the sheet structure formed by Nylon-6. ${ }^{108}$ Each polymer chain of Nylon-2 (polyglycine) hydrogen-bond to its 6 closest neighbors. No hydrogens are shown and hydrogen bonds are indicated by dashed lines.

cylglycine residue induces a helical structure in polyamides to form three-dimensional hydrogen-bond networks. ${ }^{107,109}$ Unlike a participation of common amino acids, this structural characteristics of the glycylglycine residue will allow the self-assembly of unique microtubes from corresponding bolaamphiphiles.

\section{Microtube Formation Mechanism}

The terminal carboxylate anions of the glycylglycine bolaamphiphiles 11(n) are gradually protonated, perhaps by the dissolution of carbon dioxide into air.105 FT-IR spectroscopic analysis of the dried microtubes actually revealed the new appearance of a $\mathrm{COOH}$ band absent for the sodium salt added initially in addition to a carbonyl-stretching band of $\mathrm{COO}^{-}$groups. Thus, all spectroscopic evidence supports the view that intralayer acid/anion intermolecular hydrogen bonds are crucial for the formation of microtubes (Figure 15a). ${ }^{104}$ Further protonation to the terminal carboxyl groups cause interlayer acid/acid interactions (Figure 15b), as is well-known for carboxylic acid dimer formation, eventually resulting in the formation of needle-shaped crystals (Figure 13b) that are projecting outward from the microtube surfaces.

It has been well documented so far that the selfassembling behavior of long-chain fatty acids is strongly dependent on the protonation degree of the terminal carboxylic acid. ${ }^{110}$ Similarly, the protonation state of the terminal carboxyl groups was found to sensitively influence the self-assembled morphologies of the present peptide bolaamphiphiles. By titrating the aqueous dispersion of the bolaamphiphile, we examined the $\mathrm{pH}$ dependence of the protonation degree $(\beta)$ for 11(n). Figure 16 displays the dependence of protonation degree $(\beta)$ on the spacer chain length for a 
(a)

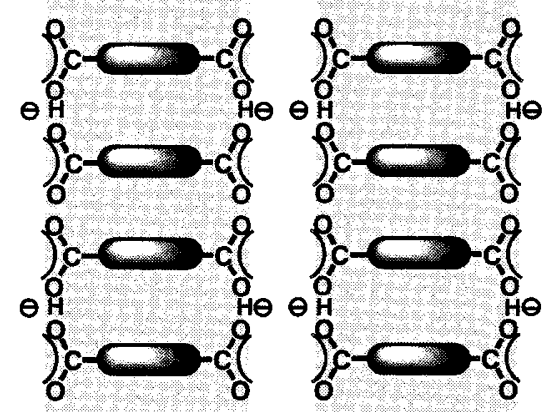

(b)

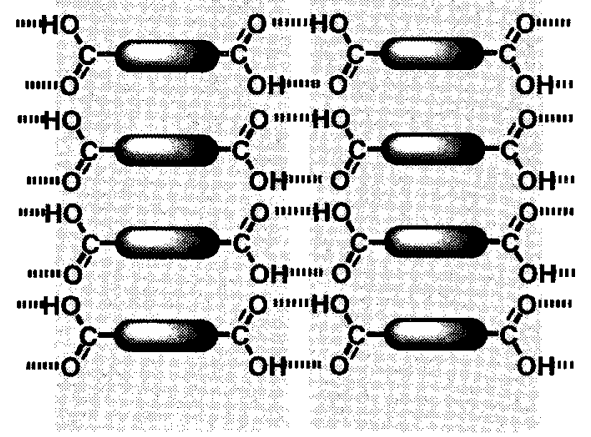

Figure 15. Schematic representation of (a) intralayer acid/anion interaction and (b) interlayer acid/acid interaction proposed for the glycylglycine bolaamphiphiles 11(n).

series of glycylglycine-based bolaamphiphiles 11(n). The obtained curve has a sigmoidal shape and is shifted to acidic $\mathrm{pH}$ with decreasing the spacer chain length, as already reported elsewhere. ${ }^{111,112}$ The longer the oligo(methylene) spacer chain length is, the more easily the bolaamphiphiles are protonated to form a carboxylic precipitate. This means that the association of longer bolaamphiphiles should be promoted due to the effective hydrophobic interaction between the alkylene chains. Microtube formation occurs just before precipitation of the acid species. The $\mathrm{pH}$ values upon the microtube formation correspond to the protonation degree $\beta=0.16-0.19$ and $\beta=0.02-0.01$ for 11(6) and 11(10), respectively.

On the basis of all FT-IR spectroscopic analysis and the $\mathrm{pH}$ dependence of the protonation behavior, we can depict the formation mechanism for the vesicle-encapsulated microtubes and the subsequent needle-shaped crystals on the microtube surfaces (Figure 17). Dicarboxylate anion species of the bolaamphiphiles exist as rod-like micelles just after the beginning of incubation (Figure 17a), as can be confirmed by cryo-transmission electron microscopy. ${ }^{104}$ Protonation of carbon dioxide into the terminal carboxylic acids immediately takes place at the fluid surfaces of the micelles and induces efficient association of charged species with uncharged ones (Figure 17b). The gradual protonation of the terminal carboxylate anion group (a)

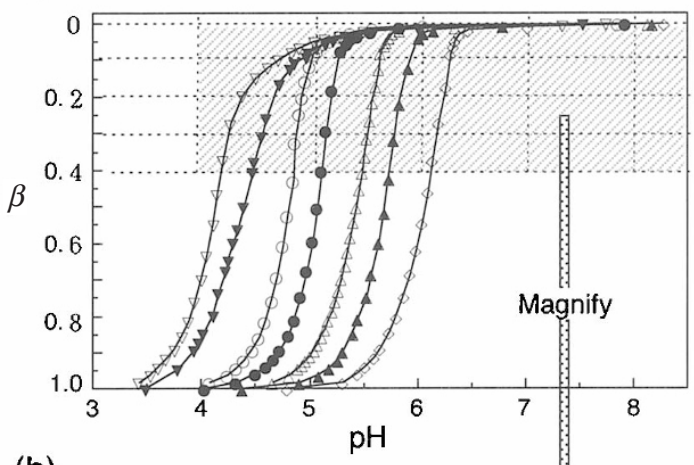

(b)

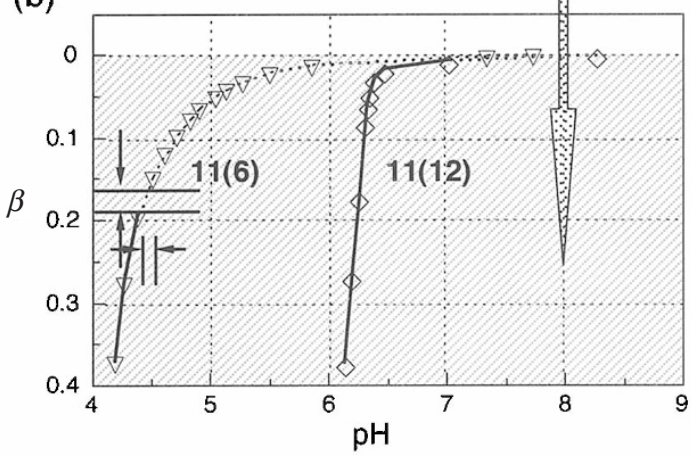

Figure 16. (a) $\mathrm{pH}$ dependence of the protonation degree $(\beta)$ when aqueous dispersions of $\mathbf{1 1}(n)(n=6-12)$ were titrated with

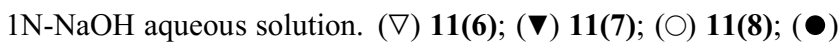

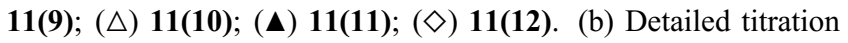
profile $(0 \leq \beta \leq 0.4)$ for 11(6) and 11(12). The $\mathrm{pH}$ and the protonation degree $(\beta)$ range, at which we observed microtubes, are denoted arrows. Appearance of the aqueous solution is clear $(\cdots)$ and opalescent (—).

causes the intralayer acid/anion interaction and eventually promotes the self-assembly into tubular morphology with the help of intermolecular hydrogen bond formation between the glycylglycine residues (Figure 17c). However, protons added externally are localizing at the headgroup surfaces. The aggregation number of the bolaamphiphiles forming the tubular morphologies gradually increases and the microtube then precipitates at a certain $\mathrm{pH}$ value due to the less solubility of the assemblies in aqueous solutions. Further protonation rearranges the hydrogen bond network from interlayer acid/anion association to intralayer acid/acid interaction to result into the growth of needle-shaped crystals on the microtube surfaces (Figure 17d). On the other hand, a defect in the inner monolayers of the microtube walls will trigger the formation of energetically favorable spherical vesicles in the aqueous environment of the hollow cylinder.

\section{Molecular Packing in a Single Crystal and in a Micro- tube}

Using slow vapor diffusion of diluted acetic acid into the aqueous solutions, we successfully ob- 
(a)

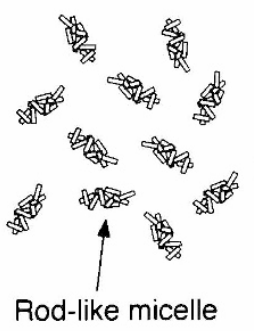

(b)

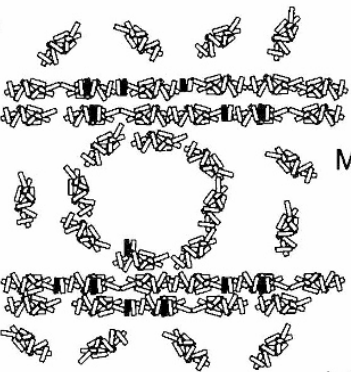

(c)

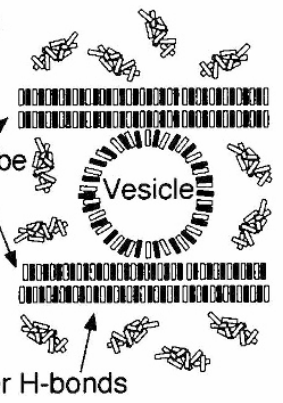

(d)

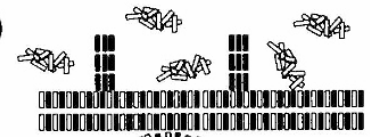

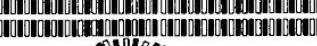

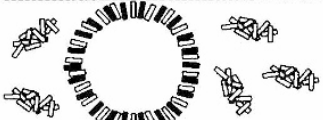

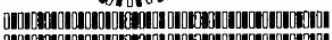

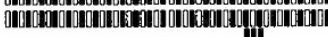

$\rightarrow$ a

Interlayer $\mathrm{H}$-bonds

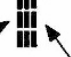

Needel

Crystal

$\square \equiv{ }^{-} \mathrm{OOC} \longrightarrow \mathrm{COO}^{-} \square \equiv \mathrm{HOOC} \longrightarrow \mathrm{COOH}$

Figure 17. Possible formation mechanism of the vesicle-encapsulated microtubes and needle-shaped crystals on the outer surfaces of the microtube.

(a)

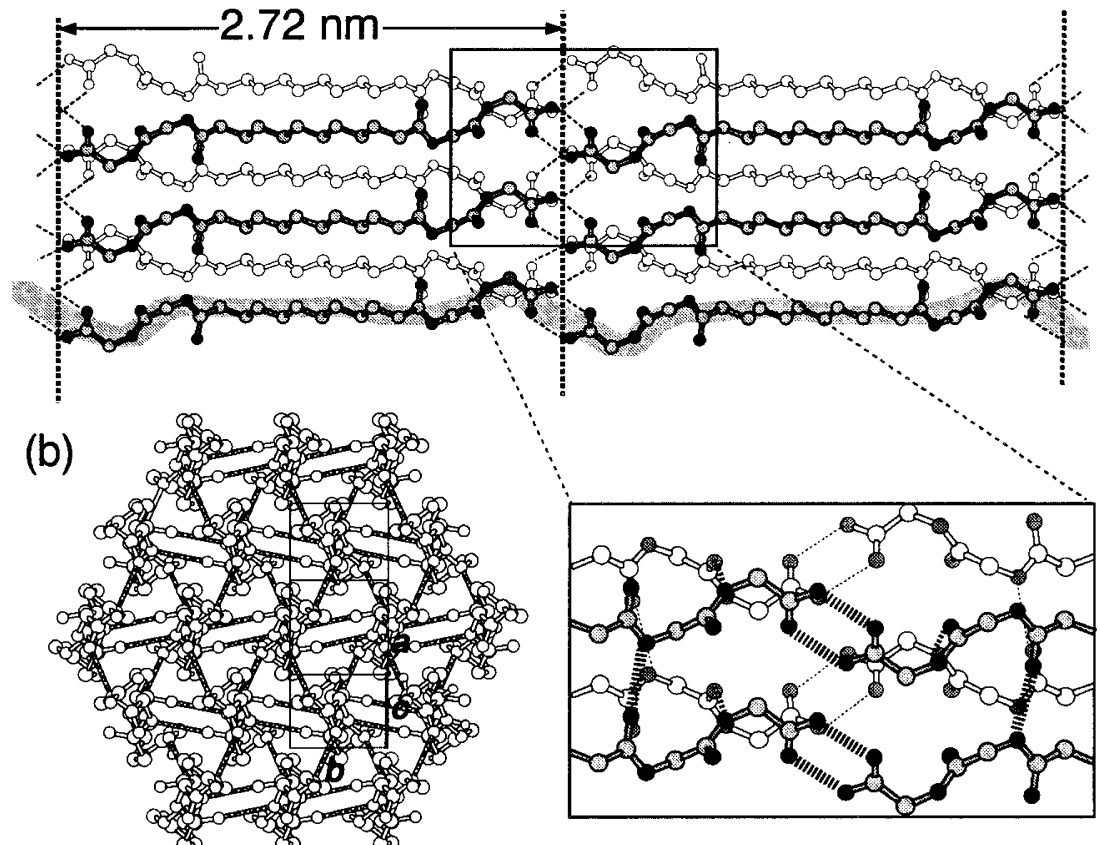

\section{: Hydrogen Bond}

Figure 18. X-Ray single crystal structure of 11(10). (a) projected on the $b c$-plane and (b) projected on the $b(2 a / 3+1 c / 8)$-plane. A gray linear band shows one-dimensional polymolecular chain formed by hydrogen bonding.

tained a single crystal of 11(10) coexisting with vesicle-encapsulated microtubes, which can be subjected to a single crystal X-Ray structural analysis. The bolaamphiphilic molecules 11(10) are found to form a layer structure with $2.72 \mathrm{~nm}$ long-range ordering in the single crystal. The terminal carboxylic acid forms intermolecular bidentate hydrogen bonds contributing to the formation of a linear polymolecular chain (Figure 18a). ${ }^{13,114}$ Interestingly, each molecule hydrogen-bonds to the surrounding six adjacent molecules through the amide functionalities of glycine residues and eventually forming a hexagonal lattice in the crystalline state (Figure 18b). The polyglycine II structure is again noted to be characterized by a nearly $120^{\circ}$ rotation between the amide carbonyl directions (Figure 14a). ${ }^{106}$ Therefore, the present findings give the first example of a polyglycine II structure formed by self-assembly of a noncovalent polymolecular chain. ${ }^{113}$

The hydrogen bond networks of 11(10) between the glycylglycine units are not completely ordered unlike in the single crystal ${ }^{114}$ since the amide $\mathrm{NH}$ group in the microtube is partly non-hydrogen-bonded. ${ }^{104}$ Highresolution atomic force microscopy (AFM) allowed us to evaluate thickness of the tube membrane to be approximately $100 \mathrm{~nm}$, corresponding to $30-40$ monolayers of a fully extended bolaamphiphile. The present AFM also revealed that the molecular headgroups are arranged in a distorted hexagonal lattice on the microtube surfaces. ${ }^{104}$ In addition, the AFM visualized 


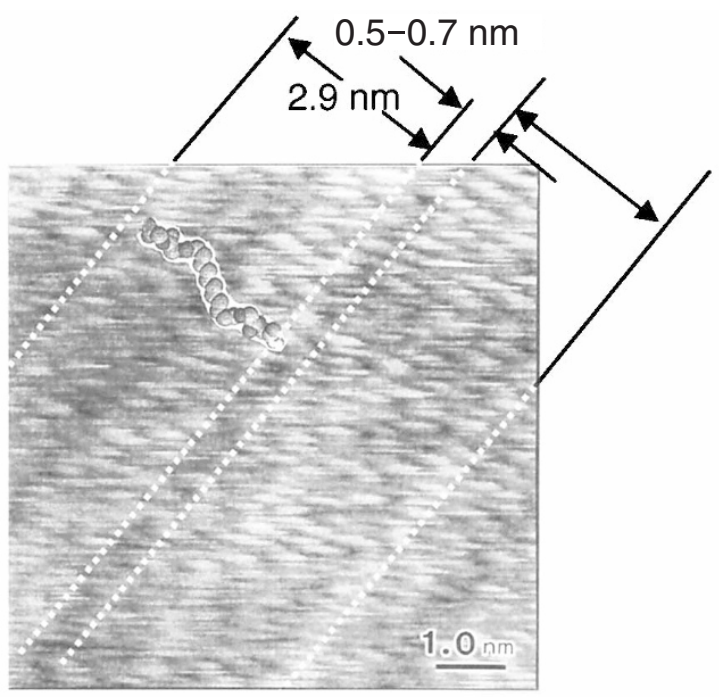

Figure 19. High-resolution atomic force microscopic (AFM) friction image $(8.0 \mathrm{~nm} \times 8.0 \mathrm{~nm})$ of the edge of the microtube membrane.

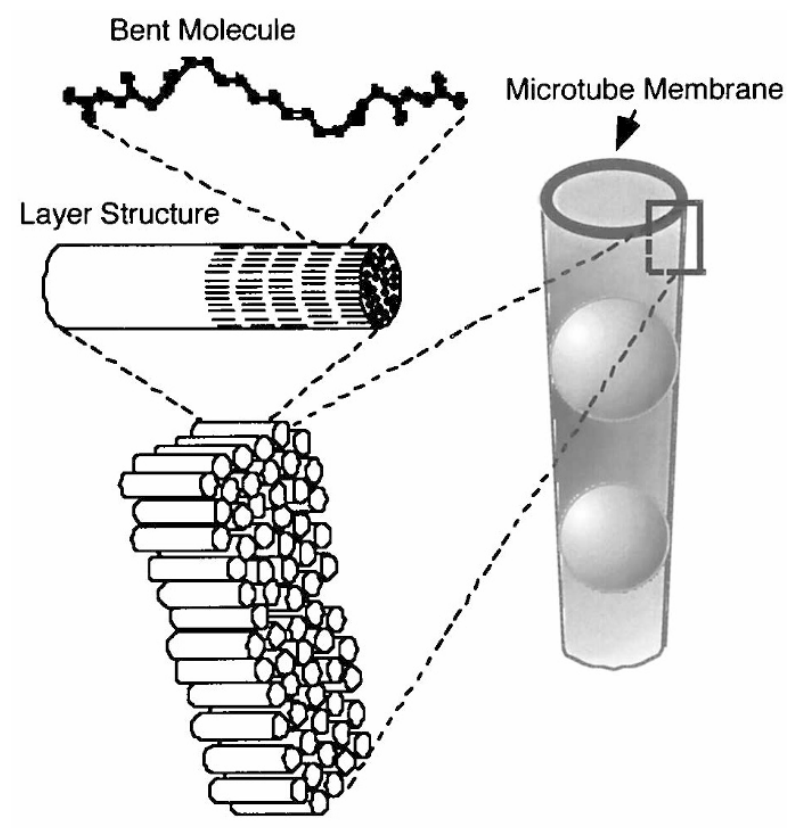

Columnar Domain

Figure 20. Schematic illustration of the observed hierarchical self-assembly of the bolaamphiphilic monomers into the microtube.

the predominance of intralayer interactions in the microtube structure, as shown in Figure 19. We were also able to observe a well-resolved hierarchical selfassembly: bent molecule $\rightarrow$ layer structure $\rightarrow$ columnar domain $\rightarrow$ tube membrane. ${ }^{115}$ Figure 20 shows a schematic illustration of the hierarchical self-assembly observed for the microtubes.

In a similar manner as the nanofiber formation of the sugar-based bolaamphiphiles $\mathbf{1}(\boldsymbol{n})$ and $\mathbf{3 ( n )},{ }^{57,60}$ we observed a remarkable even/odd effect on microtube formation for the series of glycylglycine-based bolaamphiphiles 11(n). Only glycylglycine bolaam- phiphiles with even-numbered or relatively shorter oligo(methylene) chains were found to give microtubes. The FT-IR band frequencies of the $\mathrm{N}-\mathrm{H}$ stretching, and the amide I and II bands clearly showed an even/odd effect for all chain lengths $(6 \leq n \leq 12)$ measured. This finding is quite different from that of 1-glucosamide bolaamphiphiles $\mathbf{1}(n)^{60}$, in which we could observe a definite even/odd effect only for the longer hydrocarbon spacers $(n \geq 10)$. Hydrogen-bond networks between oligopeptide moieties should play an important role in determining the spacer conformation of the oligo(methylene) chain. ${ }^{79}$

\section{Nanofiber Formation from C-Terminated Valylvaline- Appended Bolaamphiphilic Monomers}

The pioneering work of Kunitake and his coworkers greatly influenced the recent progress in the self-assembly studies of peptide-containing amphiphiles. ${ }^{29,30,116-118}$ In particular, dipeptide-, ${ }^{119}$ tripeptide-, ${ }^{61,62,120}$ and polypeptide-appended amphiphiles $^{121}$ are known to shape interesting, well-defined self-assembled morphologies, such as helical fibers, rods, and vesicles through self-assembly. Furthermore, the fiber formation of peptide amphiphiles is of great interest since it is closely related to $\beta$-sheet self-assemblies within amyloid fibrils. ${ }^{61,62,122,123}$ Peptide amphiphiles can thus producing diverse peptide surfaces and architectures favorable for the understanding of biological phenomena. Actually, the two- and three-dimensional structures of the peptide headgroup should significantly influence the resultant self-assembled morphologies. Typical examples include twisted and coiled helical ribbon structures self-assembled from oligo(sarcosine)- and oligo(L-proline)-containing peptide amphiphiles, respectively. ${ }^{61,62}$ If the hydrophilic part in bolaamphiphiles includes a dicarboxylic functionality, the resulting intra- and interlayer hydrogen-bond networks should dominate the self-assembled structures and morphologies. ${ }^{104}$

With this background in mind, we introduced a $\beta$-sheet-forming L-valyl-L-valine residue, as an alternative for the glycylglycine fragment that forms a hexagonal-type hydrogen bond network, into the headgroup at each end of the peptide bolaamphiphiles. Thus, we synthesized $C$-terminated valylvaline-appended bolaamphiphiles $\mathbf{1 7 ( n )}$ with a carboxylic acid group at each end (Scheme 5). ${ }^{124}$ The bolaamphiphile 17(6) produced a crystalline precipitate through self-assembly whereas $\mathbf{1 7}(\boldsymbol{n})(n \geq 7)$ gave a hydrogel consisting of a great number of nanofibers of 10 $15 \mathrm{~nm}$ widths and $0.1-10 \mu \mathrm{m}$ lengths. FT-IR displayed that the valylvaline moiety is forming a $\beta$-sheet struc- 


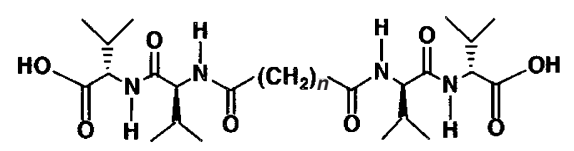

17(n): $(n=4,5,6,7,8,9,10,11$, and 12)
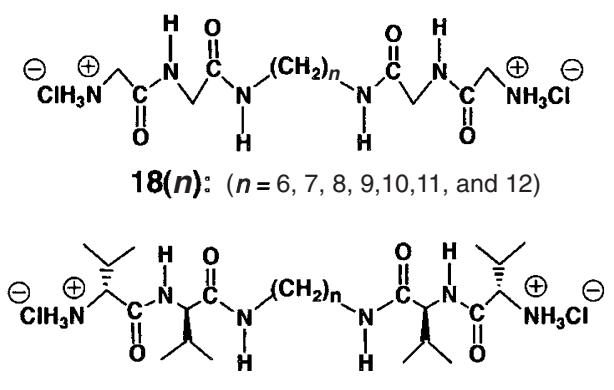

$19(n):(n=8,10$, and 12)

Scheme 5.

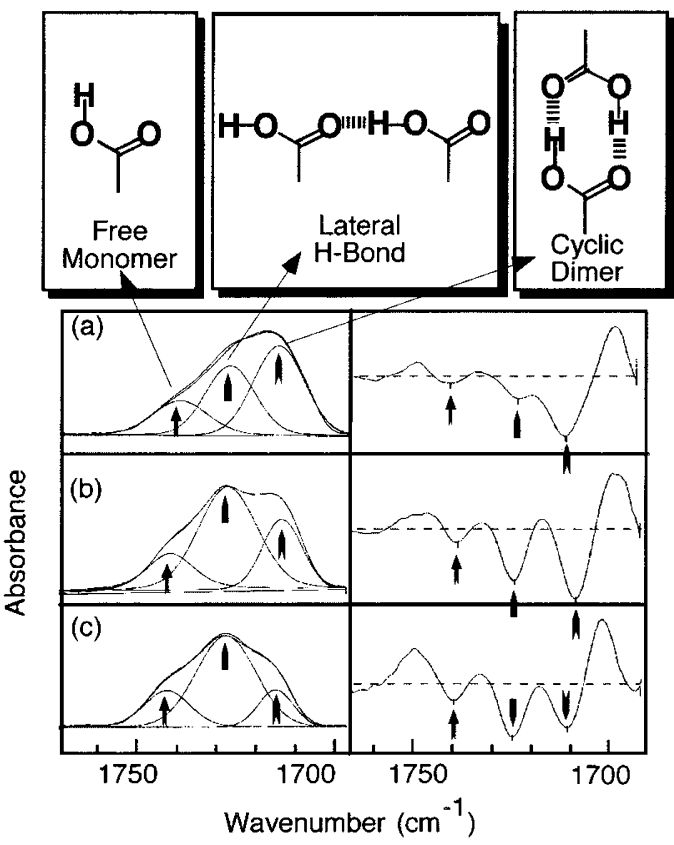

Figure 21. FT-IR spectra in the carboxyl regions of the selfassemblies from (a) 17(6), (b) 17(8), and (c) 17(10). The $\mathrm{COOH}$ band can be deconvoluted by curve-fitting analysis (left) and second-derivative plots (right).

ture in all of the self-assemblies as predicted. However, FT-IR spectra of the carbonyl regions revealed a remarkable difference in the interlayer interaction between the short- $(n=6)$ and long-chain homologues $(n \geq 7)$ (Figure 21). From the detailed analysis of the $\mathrm{C}=\mathrm{O}$ stretching band, we found that intralayer lateral acid/acid hydrogen bonds within a monolayer are dominant in nanofiber structures formed from the longer homologues. On the other hand, the shorter derivatives 17(4) and 17(6) dominated by interlayer hydrogenbond interaction were found to produce non-fibrous crystals.
$N$-Terminated Oligopeptide-Appended Bolaamphiphilic Monomers

We also prepared $N$-terminated diaamonium-type oligopeptide-appended bolaamphiphiles $\mathbf{1 8 ( n )}$ and 19(n) with either glycylglycine or L-valyl-L-valine residue at each end (Scheme 5). ${ }^{125}$ In contrast to the protonation-triggered self-assembly of the $C$-terminated bolaamphiphiles, dehydrochlorinationdriven self-assembly can be expected for these $\mathrm{N}$ terminated homologues. ${ }^{104,124}$ As a result, we found that only valylvaline-appended bolaamphiphile 19(n) with an even number of oligo(methylene) chains selfassembled into nanofiber structures in aqueous solutions. The $N$-terminated glycylglycine bolaamphiphile 18(n) gave a ribbon or sheet structure with slightly curved edge, which contrasts to the well-defined microtubular structures. The intermolecular interactions between the peptide residues and those between the oligo(methylene) chains should be structurally identical for 11(n) and 18(n). Therefore, we conclude that only the difference in the terminal hydrogen bond motif is very crucial for the formation of different type of self-assembled morphologies.

\section{NUCLEOBASE-APPENDED BOLAAMPHIPHILIC MONOMERS}

Double-Helical Rope and Nanofiber Formation from Nucleobase-Appended Bolaamphiphilic Monomers

Molecular recognition-driven self-assembly through the formation of complementary hydrogen bonds is expected as a potent strategy for the construction of welldefined nanostructures. ${ }^{36,37,52,126-129}$ We can refer to supramolecular liquid crystals, ${ }^{39,40,130}$ supramolecular fibers and membranes, ${ }^{51,131}$ two-dimensional monolayers, ${ }^{132-134}$ and supramolecular polymers ${ }^{26}$ as typical studies in line with that concept. The most sophisticated system will be double helical DNA structures stabilized by base pairing and aryl stacking between adjacent base pairs. ${ }^{135}$ Individual base pairing between the nucleobases is, however, generally performed only in aqueous solutions in the presence of a double-stranded polynucleotide chain. ${ }^{136,137}$ We have recently achieved an unprecedented hierarchical selfassembly of high-axial-ratio nanostructures using complementary thymine/thymine, thymine/adenine, and adenine/adenine internucleobase interactions. ${ }^{138}$

We have synthesized 1, $\omega$-homo-ditopic and 1, $\omega$ heteroditopic nucleobase-appended bolaamphiphiles $\mathbf{2 0}(n), \mathbf{2 1}(n)$, and $\mathbf{2 2 ( n )}$, in which the thymine or adenine derivatives are connected to both ends of the 

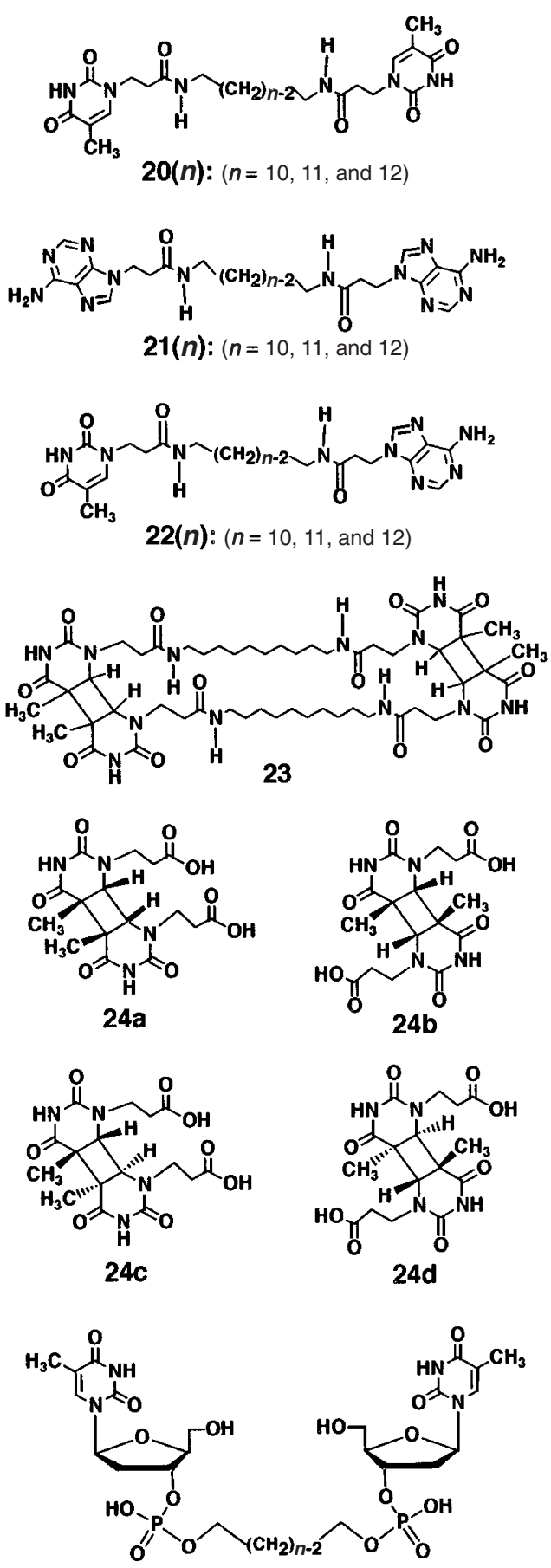

$25(n):(n=12,13,14,15,16,18$, and 20$)$

Scheme 6.

oligo(methylene) spacer (Scheme 6). ${ }^{138}$ In analogy with a polynucleotide DNA chain, one may envisage that a linear amide hydrogen bond chain should facilitate nucleobase stacking and interactions of the present bolaamphiphiles even in the absence of the normally present sugar-phosphate structures. Furthermore, this family of nucleobase bolaamphiphiles has the advantage that the effect of inter-nucleobase interaction forces on the self-assembled morphologies can be compared with keeping the terminal nucleobase un- charged. This advantage implies that the strength of inter-nucleobase interactions is tunable by changing the combination of the base pairing: with the strength being enhanced in the order pyrimidine/pyrimidine < purine/pyrimidine < purine/purine. ${ }^{139,140}$

Homoditopic adenine bolaamphiphile 21(10) selfassembled in a $10 \%$ ethanolic aqueous solution to form a microcrystalline precipitate with $1-10 \mu \mathrm{m}$ in size, whereas the thymine homologue 20(10) produced double-helical ropes of $1-2 \mu \mathrm{m}$ width and several hundred $\mu \mathrm{m}$ length through self-assembly. ${ }^{138}$ Table III summarizes the obtained self-assembled morphologies from a series of nucleobase- and nucleotideappended bolaamphiphiles. These double-helical architectures correspond to 100 times as large as DNA double helices and may give the first example of micrometer-sized double helices generated through self-assembly. ${ }^{48,141,142}$ The helical ropes are thermally and physically very stable in solution even after one year. The total number of left-handed and right-handed double-helical ropes, estimated using light microscopic images, indicated an approximately even preference for each rope. High-resolution EF-TEM showed that two independent ropes with the same helical sense are consisted of nanofiber $(10-15 \mathrm{~nm})$ bundles and helically interwoven with each other (Figure 22a). It should be noted here that a 1:1 mixture of homoditopic adenine 21(10) and thymine bolaamphiphiles 20(10) only produced nanometer-sized fibers $(10-20 \mathrm{~nm}$ in width) instead (Figure 22b), different from the doublehelical ropes observed for the thymine bolaamphiphiles 20(10). This finding clearly indicates an inhibition of double-helical rope formation of the thymine bolaamphiphile in the presence of the complementary adenine homologue.

\section{Nanofiber Formation and Inhibition Mechanism}

Enantiomeric amphiphiles should form mirror-imaged molecular assemblies. ${ }^{48,49,60,63,64,96,141,143-146}$ Therefore, the present double-helical rope formation from achiral thymine bolaamphiphile $\mathbf{2 0 ( 1 0 )}$ is incompatible with the well-known general findings mentioned above. It is known that pyrimidine bases reversibly photodimerize by irradiation with higherwavelength UV light $(\lambda>270 \mathrm{~nm}) .{ }^{147}$ The photodimerization of thymine derivatives produces four different stereoisomers among which cis-anti- and transsyn-type isomers are chiral. ${ }^{148}$ Therefore, as a useful reference of photoreacted compounds we synthesized macrocyclic photodimer mixtures $\mathbf{2 3}$ of thymine bolaamphiphiles and photodimeric mixtures of 1-(2carboxyl-ethyl)thymine $\mathbf{2 4 a - 2 4 d} .^{149}$ Thus, we were able to compare ${ }^{1} \mathrm{H}$ NMR spectra of isolated double- 
Table III. Representative self-assembled morphologies from nucleotide-appended bolaamphiphilic monomers

\begin{tabular}{cllccc}
\hline Amphiphile & $\begin{array}{c}\text { Self-assembled } \\
\text { morphology }\end{array}$ & Solvent & Width $(\mathrm{nm})$ & Length $(\mu \mathrm{m})$ & Ref \\
\hline $\mathbf{2 0}(\mathbf{1 0})$ & Double-helical rope & water/ethanol $(9 / 1)$ & $200-1000$ & ca. 1000 & 128 \\
$\mathbf{2 1}(\boldsymbol{n})(n=10,11,12)$ & Microcrystal & water/ethanol $(9 / 1)$ & $10^{3}-10^{4}$ & $1-10$ & 138 \\
$\mathbf{2 2 ( 1 2 )}$ & Nanofiber & water/ethanol $(1 / 1)$ & $15-150$ & $15-100$ & 138 \\
$\mathbf{2 0}(\mathbf{1 0}) / \mathbf{2 1}(\mathbf{1 0})$ & Nanofiber & water/ethanol $(9 / 1)$ & $15-30$ & $1-10$ & 138 \\
$\mathbf{2 5}(\mathbf{2 0})$ & Nanofiber & water (pH 4-9) & $15-30$ & $1-10$ & 169 \\
\hline
\end{tabular}

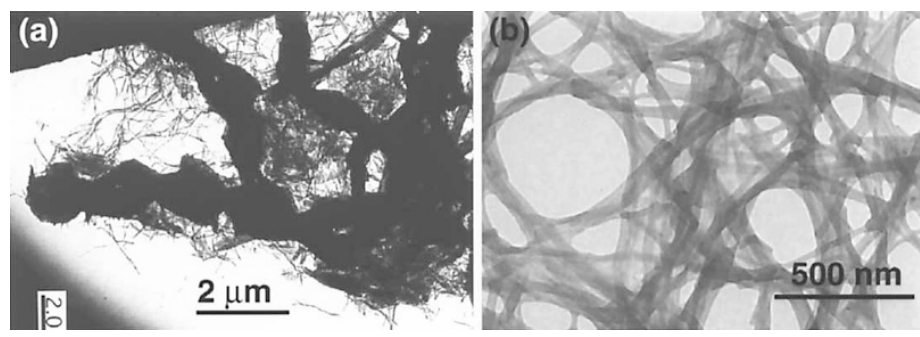

Figure 22. EF-TEM images of (a) double-helical ropes made of 20(10) and (b) nanofibers formed from a $1: 1$ mixture of $\mathbf{2 0}(\mathbf{1 0})$ and 21(10).

helical ropes with those of identified photodimerized derivatives 23 and $\mathbf{2 4 a}-\mathbf{2 4 d}$. ${ }^{1} \mathrm{H}$ NMR spectra revealed that trace amounts of photodimeric impurities are generated from thymine bolaamphiphile $\mathbf{2 0 ( 1 0 )}$ in the double-helical ropes during incubation under natural light, which correspond to macrocyclic dimer 23. From the detailed ${ }^{1} \mathrm{H}$ NMR analyses (Figure 23), we concluded that the most plausible candidate for the trigger substance is a chiral trans-syn isomer of $\mathbf{2 3}$. The neighboring thymine residues thus photodimerized and the resultant, enantiomeric photoreacted cyclic dimers triggered the formation of mirror-imaged double-helical ropes. On the other hand, when the complementary adenine derivative is coexisting, the thymine moiety takes an orientation unfavorable for photodimerization due to the formation of complementary A-T base pairing. That should be the reason why the hetero-assembly of thymine and adenine bolaamphiphiles produced no helical self-assembled structures.

Homo-assembly of heteroditopic 1, $\omega$-thymine/adenine bolaamphiphiles is characteristic of a $1: 1$ heteroassembly of homoditopic $1, \omega$-thymine and $1, \omega$-adenine bolaamphiphiles. However, no remarkable nanofiber formation was observed for the relatively shorter $1, \omega$ thymine/adenine bolaamphiphiles $\mathbf{2 2 ( n )}(n=10$ and 11). However, the longer derivative 22(12) having a dodecamethylene spacer was found to produce nice nanofibers through homo-assembly. Inter-nucleobase interaction strength and composition sensitively affect the hetero- and homo-assembled morphologies.

FT-IR spectrum and powder X-Ray diffraction pattern of the $1: 1$ hetero-assembly of 20(10) and 21(10) gave different features from those of the single components, indicating the formation of complementary

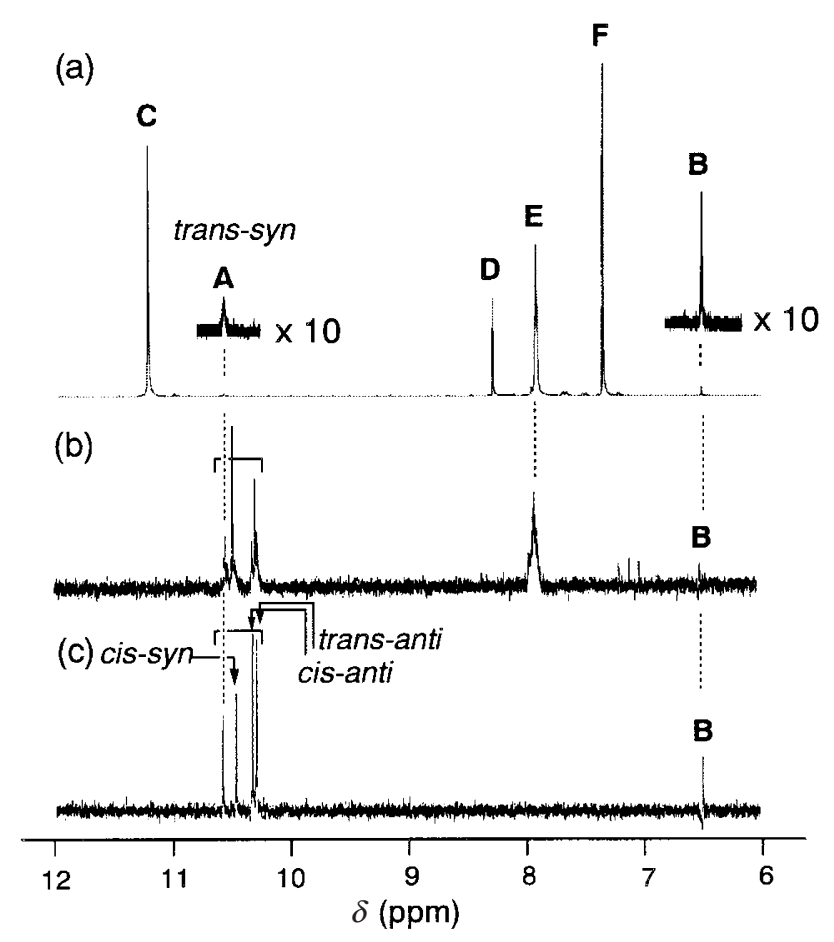

Figure 23. $600 \mathrm{MHz}$ partial ${ }^{1} \mathrm{H}$ NMR spectra of (a) dried double helical ropes of $\mathbf{2 0 ( 1 0 )}$, (b) macrocyclic photodimers $\mathbf{2 3}$, and (c) photodimers of the carboxyethyl thymine derivative $\mathbf{2 4 a - 2 4 d}$. New signals generated by the photoreaction are denoted by the symbols $\mathbf{A}$ and $\mathbf{B}$. The symbols $\mathbf{C}, \mathbf{D}, \mathbf{E}$, and $\mathbf{F}$ indicate nonhydrogenbonded-, hydrogen-bonded thymine imide $\mathrm{N}-\mathrm{H}$, amide $\mathrm{N}-\mathrm{H}$, and thymine ring $\mathrm{C}-\mathrm{H}$ protons of $\mathbf{2 0}(\mathbf{1 0})$, respectively.

thymine/adenine base pair. The hetero-assemblies proved to form lamellar organization with $5.06 \mathrm{~nm}$ long-range ordering. Thus, linear amide hydrogen bond chains much contribute to stabilize both the stacking interaction of nucleobase and the double-chain internucleobase hydrogen bonding, as shown in Figure 24. 


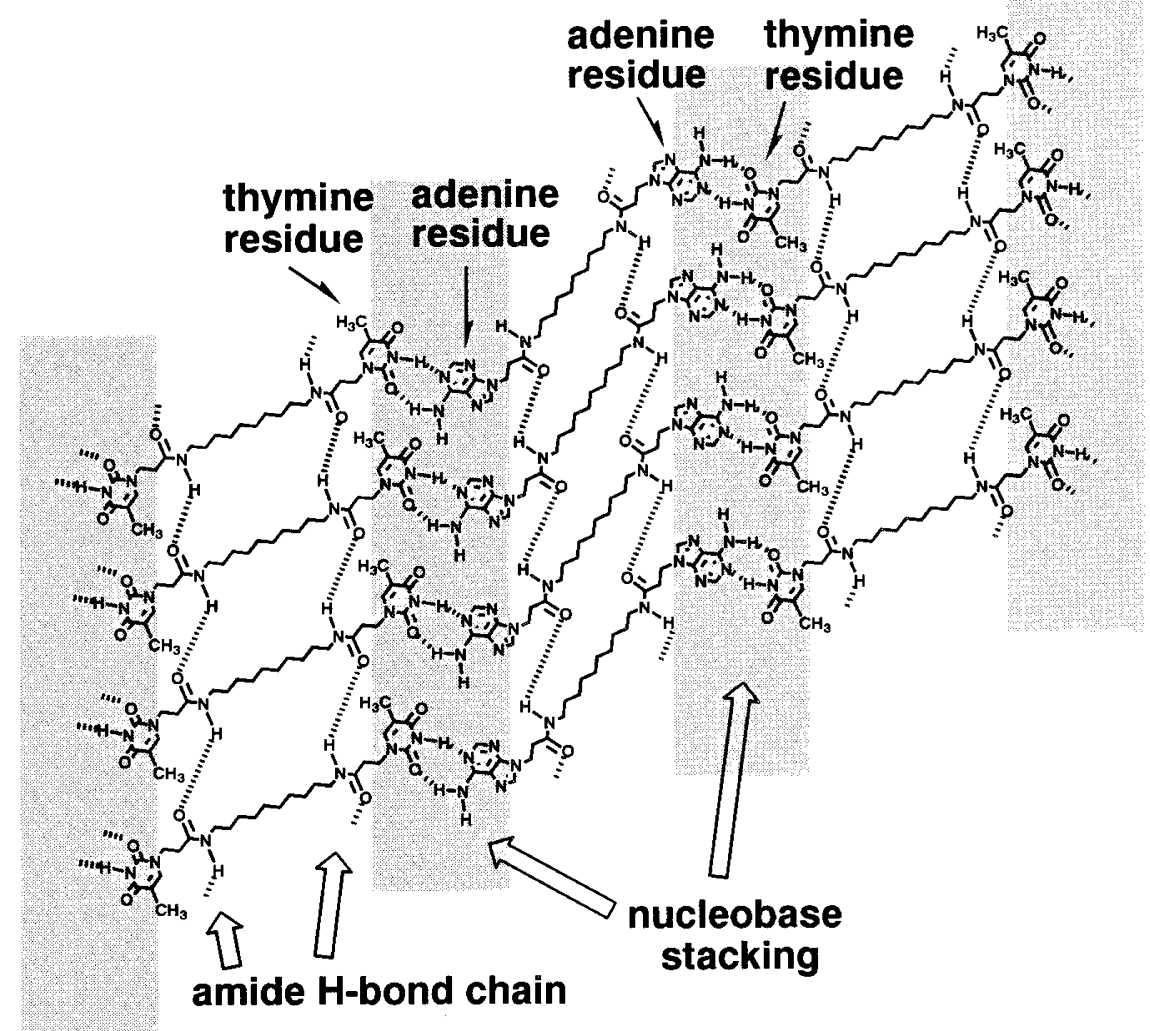

Figure 24. A possible hydrogen bond scheme for the hetero-assembly formed from a $1: 1$ mixture of 20(10) and 21(10).

\section{Nanofiber Formation from Nucleotide-Appended Bo- laamphiphilic Monomers}

Though wide variety of polymeric hydrogelators have been developed, ${ }^{150-153}$ to date there have been few examples of nonpolymeric hydrogels spontaneously formed from small molecules. ${ }^{154-162}$ We recently proposed the following three requirements for the rational design of efficient low molecular weight hydrogelators: (i) the introduction of additional hydrogen bond functionalities into an amphiphile ${ }^{155,159,160}$ (ii) the presence of chiral centers, ${ }^{154,156,157}$ and (iii) a bola-form amphiphile rather than mono-head homologue. ${ }^{155,156,158,160,161,163} \mathrm{Nu}$ cleotides, having the greatest variety of hydrogen bonding functional groups, can be very useful as a programmable headgroup in terms of the molecular design of building block toward molecular recognitiondriven self-assembly. ${ }^{164-168}$ Considering these motivation, we newly synthesized nucleotide-appended bolaamphiphiles 25(n) $(n=12-20)$, in which two 3 -phosphorylated thymidine moieties are connected to both ends of a long oligo(methylene) spacer (Scheme 6). Their self-assembling behavior in aqueous solutions was investigated in terms of gelling ability of water molecules as well as self-assembled fiber forma- tion.

The gelation behavior of the nucleotide bolaamphiphiles 25(n) was found to be strongly dependent on the $\mathrm{pH}$ of the aqueous solutions used and the oligo(methylene) spacer lengths. ${ }^{169}$ In particular, the longer homologue 25(20) can form robust hydrogels with Mill-Q water and the buffer solutions $(>\mathrm{pH}$ 4.01) (Figure 25). We found that the gelation of water by $\mathbf{2 5 ( 2 0 )}$ can be achieved even at concentrations of $0.2 \mathrm{wt} \%$ ( $>25000$ water molecules per hydrogelator molecule). The gel-to-sol transition temperature of $25(20)$ was determined to be approximately $85^{\circ} \mathrm{C}$, showing a much higher value among those reported so far. ${ }^{155,159,161}$

EF-TEM displayed the existence of intertwined nanofibers with well-defined size dimensions of $c a .10$ $30 \mathrm{~nm}$ in diameter and several micrometers in length, which eventually form developed nanofiber networks. From the scanning electron and atomic force microscopic analyses, we found that no remarkable, helically twisted fiber morphologies ${ }^{170,171}$ are observable (Figure 26). In order to get further insight into the molecular packing and orientation within the nanofibers, we measured X-Ray diffraction of a freeze-dried hydrogel of 25(20). A sharp reflection peak appears at $d=3.59 \mathrm{~nm}$ in the small angle region together with 

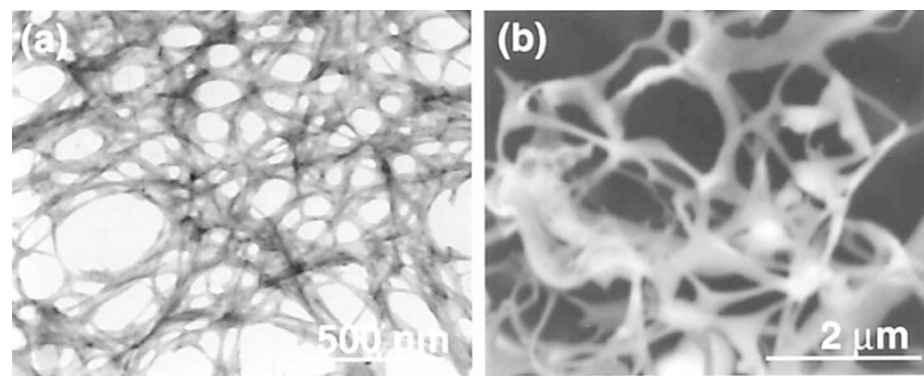

Figure 26. (a) TEM and (b) SEM images of hydrogel from 25(20), which consists of intertwined nanofibers.

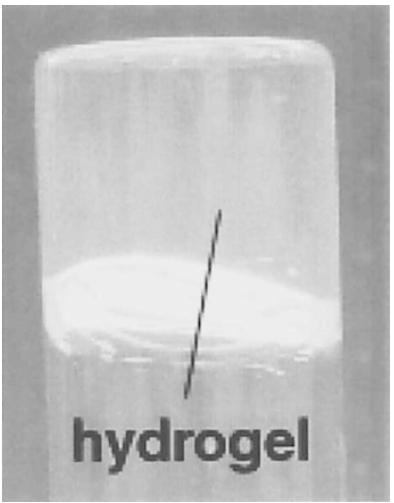

Figure 25. Stable hydrogel formed from 25(20), which can be turned upside down without any mass flow (conc. $=0.2 \mathrm{wt} \%$ ).

a single broad reflection band at around $d=0.43 \mathrm{~nm}$. Thus, we proposed a possible view that the molecules are arranged parallel with respect to the normal to the monolayer plane with a long-range ordering of $3.59 \mathrm{~nm}$. Molecular mechanics calculation using the dynamics and the molecular force field gave a minimized conformation of 25(20), in which the $C 3^{\prime}$-end puckering of the deoxyribose ring and an anti-orientation of the base relative to the sugar moiety (Figure 27) ${ }^{38}$ The evaluated molecular length $(3.51 \mathrm{~nm})$ is compatible with the $3.59 \mathrm{~nm}$ long-range ordering. Furthermore, the minimized structure indicated that two hydroxyl groups of the phosphate and the deoxyribose moieties are exposing to aqueous environment whereas the thymine group is shielded from that. This situation is much favorable for the effective hydrogen bonding to water molecules, leading to efficient hydrogelation.

\section{CONCLUDING REMARKS}

A variety of bolaamphiphiles, in which sugar-, peptide- and nucleobase-based headgroup is connected to each end of a hydrophobic spacer like oligo(methylene) via amide linkage, were designed and synthesized. Glucopyranose-appended bolaamphiphiles self-assembled in water to form helical fibers characterized by both nanometer-sized widths and the axial ratios of more than 1000 , strongly depending on the carbon numbers and even-odd num-

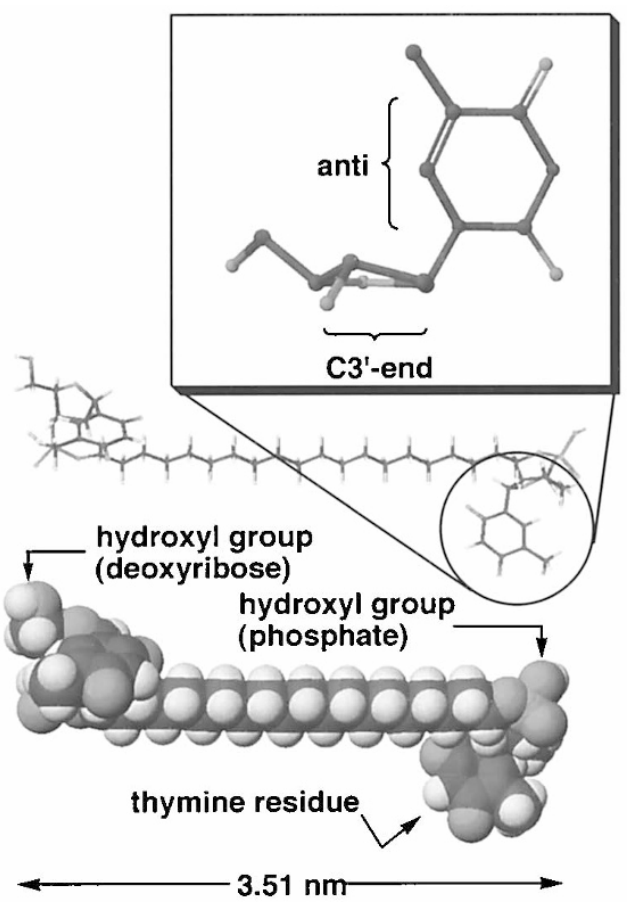

Figure 27. Computer-minimized structure of 25(20) with a hooklike conformation at each end. Detailed conformation of the nucleoside moiety using a wire molecular model is also shown, where hydrogens are omitted to simplify.

bers of the connecting oligo(methylene). Incorporation of 1,4-butadiyne moiety into the spacer hydrocarbon enabled us to obtain a single polydiacetylenic chain through the self-assembly of the monomers and the subsequent polymerization in nanometer-sized fibers. Bolaamphiphiles with glycylglycine residue as a hydrophilic headgroup gave unprecedented vesicleencapsulated microtubes that are thermally and physically very stable in aqueous solutions. Thymineappended bolaamphiphiles spontaneously assembled to form micrometer-sized double helical ropes, which was driven by the generation of trace amounts of enantiomeric photodimer impurities. Finally, bolaamphiphiles with 3 '-phosphorylated thymidine moieties as headgroups proved to be capable of gelling water very effectively through spontaneous formation of a fibrous network. Surprisingly, size distribution of all the obtained nanostructures was essentially the 
same as that of self-assembled fibrous protein structures like collagen fibers, flagella, and actin fibers, and their morphologies were found to strongly depend on the chain length and even-odd carbon numbers of used oligo(methylene) spacers. The subtle balance of inter- and intralayer interactions of monolayers are noted to be major determinants of fiber morphology as well as the hydrogen bond network between the headgroups. These fibrous self-assemblies are constructed hierarchically in a manner similar to biological structures. Furthermore, the recently developed, selfassembled nanotube structures from synthetic glycolipids ${ }^{171}$ proved to be the final expression of molecular chirality at supramolecular level ${ }^{172}$ since coiled helical ribbon structures as an intermediate finally transform into tubular structures (not mentioned). Organic selfassembled HARNs are, thus, now greatly contributing to the exploitation of quite novel nanostructures with well-controlled morphologies, ${ }^{173-176}$ inorganic building blocks, ${ }^{177,}{ }^{178}$ and diverse functionalities. ${ }^{179}$

Acknowledgment. The author very much thanks his colleagues Dr. Mitsutoshi Masuda, Masaki Kogiso, Dr. Masumi Asakawa, Dr. Hiroyuki Minamikawa, and Ms. Rika Iwaura for their continuous support at NARC, AIST during the course of this work. Grateful acknowledgement is also made to Drs. Kiyoshi Yase (AIST), Takeshi Hanada (Osaka Univ.), Yuji Okada (NIMC), and Kaname Yoshida (AIST) for their excellent TEM measurement. Drs. Midori Goto (AIST), Kazumasa Honda (AIST), and Motonari Shibakami (AIST) are thanked for valuable discussions on X-Ray structural analyses. Dr. Satomi Ohnishi is thanked for collaboration on the AFM measurement. Drs. George John and Jong Hwa Jung (CREST-JST) are acknowledged for collaboration on the self-assembled tubular materials. Dr. Michihiko Asai (AIST) is greatly thanked for collaboration on Advanced Industrial Technology Research "Multi-Dimensional Polymer Structures" supported by NEDO.

\section{REFERENCES}

1. E. Baer, A. Hiltner, and H. D. Keith, Science, 235, 1015 (1987).

2. D. A. Tomalia, A. M. Naylor, and A. Goddard, Angew. Chem., Int. Ed. Eng., 29, 138 (1990).

3. C. J. Hawker and J. M. J. Frechet, J. Am. Chem. Soc., 112, 7638 (1990).

4. T. M. Miller, Chem. Mater, 2, 346 (1990).

5. A. W. Bosman, H. M. Janssen, and E. W. Meijer, Chem. Rev., 99, 1665 (1999).

6. J.-P. Majoral and A.-M. Caminade, Chem. Rev., 99, 845 (1999).
7. S. C. Schülter, Adv. Mater., 3, 282 (1991).

8. H. Oike, H. Imaizumi, T. Mouri, Y. Yoshioka, A. Uchibori, and Y. Tezuka, J. Am. Chem. Soc., 122, 9592 (2000).

9. F. Wang, R. D. Rauh, and T. L. Rose, J. Am. Chem. Soc., 119, 11106 (1997).

10. J. Roovers, L.-L. Zhou, P. M. Toporowski, M.v.d. Zwan, H. Iatrou, and N. Hadjichristidis, Macromolecules, 26, 4324 (1993).

11. R. B. Grubbs, C. J. Hawker, J. Dao, and J. M. J. Frechet, Angew. Chem., Int. Ed. Eng., 36, 270 (1997).

12. R. Taylor and D. R. Walton, Nature, 363, 685 (1993).

13. I. Amato, Science, 254, 30 (1991).

14. D. B. Amabilino, I. W. Parsons, and J. F. Stoddart, TRIP, 2, 146 (1994).

15. C. Hamers, F. M. Raymo, and J. F. Stoddart, Eur. J. Org. Chem., 2109 (1998).

16. T. Ichi, J. Watanabe, T. Ooya, and N. Yui, Biomacromolecules, 2, 204 (2001).

17. H. Okumura, M. Okada, Y. Kawaguchi, and A. Harada, Macromolecules, 33, 4297 (2000).

18. Y. Okumura and K. Ito, Adv. Mater., 13, 485 (2001).

19. N. Yamaguchi and H. W. Gibson, Angew. Chem., Int. Ed. Eng., 38, 143 (1999).

20. C. Hamers, O. Kocian, F. M. Raymo, and J. F. Stoddart, $A d v$. Mater., 10, 1366 (1998).

21. J.-L. Weidmann, J.-M. Kern, J.-P. Sauvage, D. Muscat, S. Mullins, W. Köhler, C. Rosenauer, H.J. Räder, K. Martin, and Y. Geerts, Chem. Eur. J., 5, 1841 (1999).

22. For example,

M. Kimura, M. Sano, T. Muto, K. Hanabusa, H. Shirai, and N. Kobayashi, Macromolecules, 32, 7951 (1999).

23. S. Kelch and M. Rehahn, Macromolecules, 30, 6185 (1997).

24. J. M. Lehn, Angew. Chem. Int. Ed. Eng., 29, 1304 (1990).

25. T. Kato and J. M. J. Frechet, J. Am. Chem. Soc., 111, 8533 (1989).

26. R. P. Sijbesma, F. H. Beijer, L. Brunsveld, B. J. B. Folmer, J. H. K. K. Hirschberg, R. F. M. Large, J. K. L. Lowe, and E. W. Meijer, Science, 278, 1601 (1997).

27. T. Shimizu, "Polymer Objects: Towards New Polymer Architectures", in "Macromolecular Science and Engineering", 2nd ed., Y. Tanabe, Ed., Springer-Verlag GmbH \& Co. KG, Berlin, 1999, p 53.

28. T. Shimizu, Macromol. Rapid Commun., 23, 311 (2002).

29. T. Kunitake, Y. Okahata, M. Shimomura, S. Yasunami, and K. Takarabe, J. Am. Chem. Soc., 103, 5401 (1981).

30. T. Kunitake, Angew. Chem., Int. Ed. Eng., 31, 709 (1992).

31. S. I. Stupp, S. Son, H. C. Lin, and L. S. Li, Science, 259, 59 (1993).

32. L. H. Radzilowski, B. O. Carragher, and S. I. Stupp, Macromolecules, 30, 2110 (1997).

33. V. Percec, C.-H. Ahn, G. Ungar, D. J. P. Yeardley, M. Moller, and S. S. Sheiko, Nature, 391, 161 (1998).

34. A. Kumar and G. M. Whiteside, Appl. Phys. Lett., 63, 2002 (1993).

35. S. R. J. Oliver, T. D. Clark, N. Bowden, and G. M. Whitesides, J. Am. Chem. Soc., 123, 8119 (2001).

36. S. C. Zimmerman, F. Zeng, D. E. C. Reichert, and S. V. Kolotuchin, Science, 271, 1095 (1996).

37. G. M. Whitesides, J. P. Mathias, and C. T. Seto, Science, 254, 
$1312(1991)$.

38. G. A. Jeffrey and W. Sänger, Ed., "Hydrogen Bonding in Biological Structures", Springer-Verlag, Gmbh \& Co. KG, Berlin, 1991.

39. J.-M. Lehn, Makromol. Chem., Macromol. Symp., 69, 1 (1993).

40. J. M. Whiteside, E. E. Simanek, J. P. Mathias, C. T. Seto, D. N. Chin, M. Mammen, and D. N. Gordon, Acc. Chem. Res., 28, 37 (1995).

41. P. Terech, in "Specialist Surfactants", 2nd ed., I. D. Robb, Ed., Blackie Academic \& Professional, 1997, pp 208-268.

42. K. Hanabusa, R. Tanaka, M. Suzuki, M. Kimura, and H. Shirai, Adv. Mater., 9, 1095 (1997).

43. K. Yoza, N. Amanokura, Y. Ono, T. Akao, H. Shinmori, M. Takeuchi, S. Shinkai, and D. N. Reinhoudt, Chem. Eur. J., 5, 2722 (1999)

44. T. Kato, H. Kihara, T. Uryu, A. Fujishima, and J. M. J. Frechet, Macromolecules, 29, 8734 (1996).

45. T. Kato and J. M. J. Frechet, in "Polymeric Materials Encyclopedia", 2nd ed., J. C. Salamone, Ed., CRC Press, Boca Raton, FL, 1996, p 8158.

46. M. C. Etter, Acc. Chem. Res., 23, 120 (1990).

47. J. C. MacDonald and G. M. Whietesides, Chem. Rev., 94, 2383 (1994).

48. J.-H. Fuhrhop and W. Helfrich, Chem. Rev., 93, 1565 (1993).

49. J.-H. Fuhrhop and J. Köning, Ed., "Membranes and Molecular Assemblies: The Synkinetic Approach", The Royal Society of Chemistry, Cambridge, 1994.

50. N. Kimizuka, T. Kawasaki, and T. Kunitake, J. Am. Chem. Soc., 115, 4387 (1993).

51. N. Kimizuka, T. Kawasaki, K. Hirata, and T. Kunitake, J. Am. Chem. Soc., 120, 4094 (1998).

52. M. R. Ghadiri, J. R. Granja, R. A. Milligan, D. E. McRee, and N. Khazanovich, Nature, 366, 324 (1993).

53. J.-H. Fuhrhop, H.-H. David, J. Mathieu, U. Liman, H.-J. Winter, and E. Boekema, J. Am. Chem. Soc., 108, 1785 (1986).

54. L. Leisoeroviz and M. Tuval, Acta Crystallogr., Sec. B., 34, 1230 (1978).

55. F. D. Lewis, J.-S. Yang, and C. L. Stern, J. Am. Chem. Soc., 118, 12029 (1996).

56. M. Masuda and T. Shimizu, J. Carbohydr. Chem., 17, 405 (1998)

57. I. Nakazawa, M. Masuda, Y. Okada, T. Hanada, K. Yase, M. Asai, and T. Shimizu, Langmuir, 15, 4757 (1999).

58. I. Nakazawa, S. Suda, M. Masuda, M. Asai, and T. Shimizu, Chem. Commun., 881 (2000)

59. T. Shimizu and M. Masuda, Mol. Cryst. Liq. Cryst., 295, 197 (1997).

60. T. Shimizu and M. Masuda, J. Am. Chem. Soc., 119, 2812 (1997)

61. T. Shimizu, M. Mori, H. Minamikawa, and M. Hato, J. Chem. Soc., Chem. Commun., 183 (1990).

62. T. Shimizu and M. Hato, Biochim. Biophys. Acta, 1147, 50 (1993)

63. N. Nakashima, S. Asakuma, and T. Kunitake, J. Am. Chem. Soc., 107, 509 (1985).

64. J.-H. Funrhop, P. Schnieder, E. Boekema, and W. Helfrich, J. Am. Chem. Soc., 110, 2861 (1988).

65. T. Shimizu, M. Shibakami, and M. Masuda, Chem. Lett., 267
(1997).

66. M. Masuda and T. Shimizu, Carbohydr. Res., 326, 56 (2000)

67. S. Amelinckx, Acta Crystallogr., 8, 530 (1955).

68. S. Amelinckx, Acta Crystallogr., 9, 16 (1956).

69. S. Amelinckx, Acta Crystallogr., 9, 217 (1956).

70. J. Schneider, C. Messerschmidt, A. Schulz, M. Gnade, B. Schade, P. Luger, P. Bombicz, V. Hubert, and J.-H. Fuhrhop, Langmuir, 16, 8575 (2000).

71. N. Yamada and M. Kawasaki, J. Chem. Soc., Chem. Commun., 568 (1990).

72. N. Yamada, K. Okuyama, T. Serizawa, M. Kawasaki, and S. Oshima, J. Chem. Soc., Perkin Trans., 2, 2707 (1996).

73. M. Masuda and T. Shimizu, Chem. Commun., 1057 (1996).

74. M. Masuda and T. Shimizu, Carbohydr. Res., 302, 139 (1997).

75. Y. Kinoshita, Makromol. Chem., 33, 21 (1959).

76. E. Benedetti, M. R. Ciajolo, and P. Coradini, Eur. Polym. J., 10, 1201 (1974).

77. Cambridge Structural Database Center, 1996, Cambridge Structural Database System Version 5.1.2., Cambridge Structural Data Center, 12 Union Road, Cambridge CB2 1EW, England.

78. G. A. Jeffrey and L. M. Wingert, Liq. Cryst., 12, 179 (1992).

79. M. Masuda, V. Vill, and T. Shimizu, J. Am. Chem. Soc., 122, 12327 (2000).

80. I. Nakazawa, S. Suda, M. Masuda, M. Asai, and T. Shimizu, Chem. Commun., 881 (2000).

81. Y. Nagai, K. Kobayashi, H. Toi, and Y. Aoyama, Bull. Chem. Soc. Jpn., 66, 2965 (1993).

82. T. J. James, K. R. A. S. Sandanayake, and S. Shinkai, Angew. Chem. Int. Ed. Engl., 35, 1910 (1996).

83. J.C. Norild and H. Eggert, J. Am. Chem. Soc., 117, 1479 (1995).

84. M. Mikami and S. Shinkai, J. Chem. Soc., Chem. Commun., 153 (1995).

85. M. Mikami and S. Shinkai, Chem. Lett., 603 (1995).

86. M. Masuda, T. Hanada, K. Yase, and T. Shimizu, Macromolecules, 31, 9403 (1998).

87. M. Masuda, T. Hanada, Y. Okada, K. Yase, and T. Shimizu, Macromolecules, 33, 9233 (2000).

88. H. Bader and H. Ringsdorf, J. Polym. Sci., Polym. Chem. Ed., 20, 1623 (1982).

89. F. Saremi, E. Maassen, B. Tieke, G. Jordan, and W. Rammensee, Langmuir, 11, 1068 (1995).

90. F. Saremi and B. Tieke, Adv. Mater, 7, 378 (1995).

91. J. H. Fendler, Acc. Chem. Res., 17, 3 (1984).

92. H. Ringsdorf, B. Schlarb, and J. Venzmer, Angew. Chem., Int. Ed. Eng., 27, 113 (1988).

93. B. Tieke and G. Wegner, in "Topics in Surface Chemistry", 2nd ed., E. Kay, P. S. Bagus, Ed., Plenum Publishing Corporation, New York, N.Y., 1978.

94. D. F. O'Brien, T. H. Whitesides, and R. T. Kingbiel, J. Polym. Sci., Polym Lett. Ed., 19, 95 (1981).

95. D. A. Frankel and D. F. O'Brien, J. Am. Chem. Soc., 113, 7436 (1991).

96. D. A. Frankel and D. F. O'Brien, J. Am. Chem. Soc., 116, 10057 (1994).

97. T. Kim, K. Chan, and R. M. Crooks, J. Am. Chem. Soc., 119, 189 (1997).

98. V. Enkelman, Adv. Polym. Sci., 63, 91 (1984). 
99. G. N. Patel, R. R. Chance, and J. D. Witt, J. Polym. Sci., Polym. Lett. Ed., 16, 607 (1978).

100. K. C. Lim and A. J. Heeger, J. Chem. Phys., 82, 522 (1985).

101. H. Nakanishi, N. Sumi, Y. Aso, and T. Otsubo, J. Org. Chem., 63, 8632 (1998).

102. S. Hung and J. M. Tour, J. Am. Chem. Soc., 121, 4908 (1999).

103. N. Aratani, A. Osuka, Y. H. Kim, D. H. Jeong, and D. Kim, Angew. Chem., Int. Ed. Eng., 39, 1458 (2000).

104. M. Kogiso, S. Ohnishi, K. Yase, M. Masuda, and T. Shimizu, Langmuir, 14, 4978 (1998).

105. T. Shimizu, M. Kogiso, and M. Masuda, Nature, 383, 487 (1996).

106. F. H. C. Crick and A. Rich, Nature, 176, 780 (1955).

107. D. R. Homes, C. W. Bunn, and D. J. Smith, J. Polym. Sci., 17, 159 (1955).

108. J. Bella, J. Puiggali, and J. A. Subirana, Polymer, 35, 1291 (1994).

109. E. Navarro, V. Tereshko, J. A. Subirana, and J. Puiggali, Biopolymers, 36, 711 (1995).

110. M. E. Feinstein and H. L. Rosano, J. Phys. Chem., 73, 601 (1969).

111. T. Imae, Y. Takahashi, and H. Muramatsu, J. Am. Chem. Soc., 114, 3414 (1992).

112. W. R. Hargreaves and D. W. Deamer, Biochemistry, 17, 3759 (1978).

113. T. Shimizu, M. Kogiso, and M. Masuda, J. Am. Chem. Soc., 119, 6209 (1997).

114. M. Kogiso, M. Masuda, and T. Shimizu, Supramol. Chem., 9, 183 (1998).

115. T. Shimizu, S. Ohnishi, and M. Kogiso, Angew. Chem., Int. Ed. Eng., 37, 3260 (1998).

116. Y. Murakami, Y. Aoyama, A. Nakano, T. Tada, and K. Fukuya, J. Am. Chem. Soc., 103, 3951 (1981).

117. T. Kunitake and N. Yamada, J. Chem. Soc., Chem. Commun., 655 (1986).

118. P. Berndt, G. B. Fields, and M. Tirrell, J. Am. Chem. Soc., 117, 9515 (1995).

119. Y. Murakami, A. Nakano, and H. Ikeda, J. Org. Chem., 47, 2137 (1982)

120. T. Shimizu, M. Mori, H. Minamikawa, and M. Hato, Chem. Lett., 1341 (1989).

121. K. Yamada, H. Ihara, T. Ide, T. Fukumoto, and C. Hirayama, Chem. Lett., 1713 (1984).

122. Y. Takahashi, A. Ueno, and H. Mihara, Chem. Eur. J., 4, 2475 (1998).

123. N. Yamada, K. Ariga, M. Naito, K. Matsubara, and E. Koyama, J. Am. Chem. Soc., 120, 12192 (1998).

124. M. Kogiso, Y. Okada, T. Hanada, K. Yase, and T. Shimizu, Biochim. Biophys. Acta, 1475, 346 (2000).

125. M. Kogiso, Y. Okada, M. Masuda, K. Yase, and T. Shimizu, Polym. Prepr. Jpn., 48, 1261 (1999).

126. J.-M. Lehn, M. Mascal, A. Decian, and J. Fischer, J. Chem. Soc., Chem. Commun., 479 (1990).

127. F. M. Menger and S. J. Lee, J. Am. Chem. Soc., 116, 5987 (1994).

128. D. Philp and J. F. Stoddart, Angew. Chem., Int. Ed. Eng., 35, 1154 (1996).

129. J. J. Storhoff and C. A. Mirkin, Chem. Rev., 99, 1849 (1999).
130. T. Kato, M. Nakano, T. Moteki, T. Uryu, and S. Ujiie, Macromolecules, 28, 8875 (1995).

131. T. Gulik-Krzywicki, C. Fouuey, and J.-M. Lehn, Proc. Natl. Acad. Sci. U.S.A., 90, 163 (1993).

132. D. Sasaki, K. Kurihara, and T. Kunitake, J. Am. Chem. Soc., 114, 10994 (1992).

133. T. Boland and B. D. Ratner, Langmuir, 10, 3845 (1994).

134. M. Shimomura, F. Nakamura, K. Ijiro, H. Taketsuna, M. Tanaka, H. Nakamura, and K. Hasebe, J. Am. Chem. Soc., 119, 2341 (1997).

135. W. Sänger, Ed., "Principles of Nucleic Acid Structure", Springer-Verlag GmbH \& Co. KG, Berlin, 1984.

136. J. S. Nowick and J. S. Chen, J. Am. Chem. Soc., 114, 1107 (1992).

137. V. M. Rotello, E. A. Viani, G. Deslongchamps, B. A. Murray, and J. Rebek, Jr., J. Am. Chem. Soc., 115, 797 (1993).

138. T. Shimizu, R. Iwaura, M. Masuda, T. Hanada, and K. Yase, J. Am. Chem. Soc., 123, 5947 (2001).

139. P. O. Ts'O and S. I. Chan, J. Am. Chem. Soc., 86, 4176 (1964).

140. M. P. Schwizer, S. I. Chan, and P. O. Ts'O, J. Am. Chem. Soc., 87, 5241 (1965).

141. H. Yanagawa, Y. Ogawa, H. Furuta, and K. Tsuno, J. Am. Chem. Soc., 111, 4567 (1989).

142. N. A. J. M. Somerdijk, P. J. J. A. Buynsters, H. Akdemir, D. G. Geurts, A. M. A. Pistorius, M. C. Feiters, R. J. M. Nolte, and B. Zwaneburg, Chem. Eur. J., 4, 127 (1998).

143. S. Svenson, B. Kirste, and J.-H. Fuhrhop, J. Am. Chem. Soc., 116, 11969 (1994).

144. T. Shimizu, Trans. Meter. Res. Soc. Jpn., 24, 431 (1999).

145. T. Tachibana and H. Kambara, J. Am. Chem. Soc., 87, 3015 (1965).

146. N. Yamada, T. Sasaki, H. Murata, and T. Kunitake, Chem. Lett., 205 (1989).

147. S. Wang, Nature, 200, 879 (1963).

148. D. L. Wulff and G. Fränkel, Biochim. Biophys. Acta, 51, 332 (1961).

149. M. J. Moghaddam, S. Hozumi, Y. Inaki, and K. Takemoto, J. Polym. Sci., Polym. Chem. Ed., 26, 3297 (1988).

150. G. Chen and A. S. Hoffman, Nature, 373, 49 (1995).

151. R. Yoshida, K. Uchida, Y. Kaneko, K. Sakai, A. Kikuchi, Y. Sakurai, and T. Okano, Nature, 374, 240 (1995).

152. C. Wang, R. J. Stewart, and J. Kopecek, Nature, 397, 417 (1999).

153. K. Lee and D. J. Mooney, Chem. Rev., 101, 1869 (2001).

154. J.-H. Fuhrhop and C. J. Böttcher, J. Am. Chem. Soc., 112, 1768 (1990).

155. G. R. Newkome, G. R. Baker, S. Arai, M. J. Saunders, P. S. Russo, K. J. Theriot, C. N. Moorefield, L. E. Rogers, J. E. Miller, T. R. Lieux, M. E. Murray, B. Phillips, and L. Pascal, J. Am. Chem. Soc., 112, 8458 (1990).

156. M. Jokic, J. Makarevic, and M. Zinic, J. Chem. Soc., Chem. Commun., 1723 (1995).

157. R. Oda, I. Huc, and S. J. Candau, Angew. Chem., Int. Ed., 37, 2689 (1998).

158. M. Kogiso, S. Ohnishi, K. Yase, M. Masuda, and T. Shimizu, Langmuir, 14, 4978 (1998).

159. S. Bhattacharya and S. N. G. Acharya, Chem. Mater, 11, 3504 (1999). 
160. L. A. Estroff and A. D. Hamilton, Angew. Chem., Int. Ed. Eng., 39, 3447 (2000).

161. F. M. Menger and K. L. Caran, J. Am. Chem. Soc., 122, 11679 (2000).

162. C. Marmillon, F. Gauffre, T. Gulik-Krzywicki, C. Loup, A.M. Caminade, and E. Rump, Angew. Chem., Int. Ed., 40, 2626 (2001).

163. J. H. Jung, S. Shinkai, and T. Shimizu, Chem. Eur. J., 8, 2684 (2002).

164. H. Yanagawa, Y. Ogawa, H. Furuta, and K. Tsuno, J. Am. Chem. Soc., 111, 4567 (1989).

165. F. Pincet, E. Perez, G. Bryant, L. Lebeau, and C. Mioskowski, Phys. Rev. Lett., 73, 2780 (1994).

166. S. Bonaccio, D. Capitani, A. L. Segre, P. Walde, and P. L. Luisi, Langmuir, 13, 1952 (1997).

167. D. Berti, P. Barbaro, I. Bucci, and P. Baglioni, J. Phys. Chem. $B, \mathbf{1 0 3}, 4916$ (1999).

168. S. L. Forman, J. C. Fettinger, S. Pieraccini, G. Gottarelli, and J. T. Davis, J. Am. Chem. Soc., 122, 4060 (2000).

169. R. Iwaura, K. Yoshida, M. Masuda, K. Yase, and T. Shimizu, Chem. Mater, 14, 3047 (2002).
170. K. Hanabusa, M. Yamada, M. Kimura, and H. Shirai, Angew. Chem. Int. Ed. Eng., 35, 1949 (1996).

171. E. Snip, S. Shinkai, and D. N. Reinhoudt, Tetrahedron Lett., 42, 2153 (2001)

172. M. C. Feiters and R. J. M. Nolte, Ed., "Advances in Supramolecular Chemistry”, JAI Press Inc., New York, N.Y., 2000, vol.6, pp 55-157.

173. G. John, M. Masuda, Y. Okada, K. Yase, and T. Shimizu, Adv. Mater., 13, 715 (2001).

174. J. H. Jung, H. Kobayashi, M. Masuda, T. Shimizu, and S. Shinkai, J. Am. Chem. Soc., 123, 8785 (2001).

175. G. John, J. H. Jung, H. Minamikawa, K. Yoshida, and T. Shimizu, Chem. Eur. J., 8, 5494 (2002).

176. J. H. Jung, G. John, K. Yoshida, and T. Shimizu, J. Am. Chem. Soc., 124, 10674 (2002).

177. J. H. Jung, S. Shinkai, and T. Shimizu, Nano Letters, 2, 17 (2002).

178. J. H. Jung, K. Yoshida, and T. Shimizu, Langmuir, 18, 8724 (2002).

179. H. Frusawa, A. Fukagawa, K. Ito, G. John, and T. Shimizu, Angew. Chem. Int. Ed. Eng., in press.

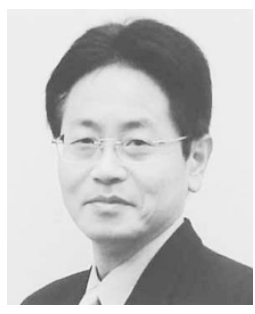

Toshimi Shimizu was born in Osaka, Japan, in 1952. He received his B.S. and M.S. degrees in Polymer Chemistry from Kyoto University, Japan in 1975 and 1977, respectively, and obtained his Ph.D. degree from Kyoto University, Japan in 1983. In 1977, he joined the Research Institute of Polymers and Textiles, Agency of Industrial Science and Technology (AIST), Ministry of International Trade and Industry (MITI), Japan. After his postdoctoral research at Free University Berlin with Prof. J.-H. Fuhrhop, he joined the National Institute of Materials and Chemical Research, AIST, MITI in 1993. Since 2001, he is the director of the Nanoarchitectonics Research Center (NARC), National Institute of Advanced Industrial Science and Technology (AIST). He is also now promoting a CREST Project entitled "Functional High-Axial-Ratio Nanostructure Assembly for Nano-Space Engineering" by Japan Science and Technology Corporation (JST) as a project director. His research focuses on the noncovalent synthesis and structural analyses of high-axial-ratio nanostructures through the self-assembly of amphiphilic monomers as well as the synthesis of mechanically linked polymers. Toshimi Shimizu is the recipient of the Minister's Award of MITI, 2000 and has been the author of over 140 publications, including original research papers, reviews, and chapters of books. He received The Award of the Society of Polymer Science, Japan (2001). 